\title{
Un instrumento de medida para conocer las tendencias de los directivos en la priorización de las acciones de Responsabili- dad Social Empresarial (RSE)
}

\section{Elsa Del Castillo Mory}

Doctora en Economía y Dirección de Empresas por la Universidad de Deusto, San Sebastián, España. Departamento Académico de Administración y Escuela de Postgrado Universidad del Pacífico

(PERÚ)

\section{Amaia Arizkuren Eleta}

Doctora en Economía y Dirección de Empresas por la Universidad de Deusto, San Sebastián, España. Facultad de CC. Económicas y Empresariales

Universidad de Deusto

(ESPAÑA)

\begin{abstract}
Resumen
La Responsabilidad Social Empresarial (RSE) ha evolucionado como concepto. En sus inicios, las menciones en la literatura sobre el tema vinculaban la RSE con los principios y valores corporativos. Con el paso del tiempo, estos principios y valores se han hecho tangibles en los sistemas de gestión empresarial. Es así que diversos instrumentos internacionales han recogido una gran variedad de prácticas deseables en los distintos ámbitos de la actuación de la empresa. Si bien existe abundancia de instrumentos, no hay evidencia de su validación en términos de rigurosidad académica. El trabajo aquí presentado ha buscado sistematizar los aportes de diversos instrumentos utilizados en el ámbito internacional, y particularmente en el de Latinoamérica, para producir una escala de medida -validada estadísticamente- que permita la priorización de acciones de RSE. A partir de la aplicación de este instrumento en una muestra de cien de las más grandes empresas que operan en el Perú, las autoras analizan la forma en que los directivos de estas organizaciones otorgan mayor o menor relevancia a los posibles campos de la actuación responsable. Una mayor comprensión de esta dinámica de decisión puede contribuir al desarrollo de mecanismos más efectivos para promover en los directivos una visión integral de la gestión de la RSE.

Los hallazgos de esta investigación dan cuenta de una visión de la RSE aún heterogénea y lejana al desarrollo de una conceptualización integral de la actuación responsable, donde el mayor énfasis está puesto en aquellas acciones directamente identificadas con el resultado económico del negocio, en contraposición a aquellas otras que fortalecen relaciones más amplias con otros grupos de interés de la empresa. Los ámbitos que obtuvieron las puntuaciones promedio más elevadas fueron: «la oferta de productos y servicios al mercado» y «la gestión interna», en contraposición con otros ámbitos que exigen una alta interacción con el entorno, como «la gestión de la cadena de suministro», «la gestión medioambiental» y «la gestión de los temas sociales».
\end{abstract}

Palabras clave: RSE, instrumento de medida, toma de decisiones. 


\section{Introducción}

Blowfield y Frynas (2005) sostienen que la RSE debiera ser entendida como un paraguas que lleve a la empresa a asumir un comportamiento responsable con todos aquellos con los que hace negocios, y que le permita desarrollar relaciones que promuevan la generación de valor para la empresa y para la sociedad. En este mismo sentido, Waddock (2004) afirma que la RSE ha ido adquiriendo una dimensión integral en torno a la actuación de la empresa y que, por ello, desde mediados de la década de los años 1990, algunos autores quitaron la palabra «social» para denominar al concepto «responsabilidad empresarial».

En el mundo empresarial, la vinculación de la RSE con la gestión corporativa ha generado espacio para que diversas iniciativas de carácter internacional desarrollen instrumentos que contribuyan a la planificación, ejecución, monitorización, evaluación y reporte de la actuación social responsable de la empresa (Hammer 2004; Instituto Ethos 2004b; Comisión Europea 2003; GRI 2002). Estas iniciativas proponen principios, guías e instrumentos que abordan los diversos ámbitos de la actuación corporativa en su camino hacia una mayor conciencia social. Según se verá más adelante, en la sección referida al marco conceptual, entre los instrumentos disponibles resaltan los códigos de conducta y principios aspiracionales; los lineamientos para una gestión responsable -y versiones puntuales sobre ciertos ámbitos de la gestión-; la estructuración de índices para la inversión sócial responsable, que analizan el desempeño de la empresa; y los marcos referenciales para la elaboración de reportes y para la rendición de cuentas. Los instrumentos propuestos, sin embargo, abordan de manera parcial la problemática analizada y no han sido expuestos a una validación estadística que permita que sean utilizados en estudios académicos con rigurosidad científica.

El carácter diferenciador del instrumento propuesto en este artículo viene dado por el desa- rrollo de un abanico amplio de acciones de RSE que abarcan los principales ámbitos de la actuación empresarial, lo que permite obtener una visión integral de las diversas dimensiones de la actuación responsable (se incluyen las variables representativas de la gestión laboral; social; medioambiental, de la ética y el gobierno corporativo; de la gestión de la oferta de productos y servicios al mercado; y, finalmente, de la gestión de la cadena de suministro). Este instrumento facilita el ejercicio de la priorización de acciones para llevar a cabo diagnósticos sobre la forma en que las empresas consideran estos aspectos en sus procesos de toma de decisiones. De acuerdo con lo mencionado, los esfuerzos por sistematizar las propuestas de las diversas entidades que han identificado modelos, instrumentos, acciones e indicadores sobre el desempeño socialmente responsable en el nivel corporativo serán de utilidad para el mundo empresarial y académico.

A continuación se describe el objetivo del estudio y se desarrolla el marco conceptual relevante, donde se presentan diversos instrumentos disponibles en la literatura y se analizan las principales variables contenidas en ellos. En una siguiente sección se presentan los principales elementos metodológicos que guiaron la construcción del instrumento para la priorización de las acciones de RSE propuesto en este artículo y, finalmente, se incluye un análisis de los resultados obtenidos con su aplicación.

\section{Objetivo del estudio}

La finalidad principal de la investigación presentada en este artículo ha sido el desarrollo de un instrumento, estadísticamente validado, que permita medir la forma en que se priorizan los posibles campos de actuación en materia de RSE. En esa dirección, este estudio busca poner a prueba el instrumento de medida, mediante su aplicación en una muestra de directivos a cargo de la gestión de la RSE en las más grandes empresas que operan en el Perú. 


\section{Marco conceptual}

El comportamiento responsable de las organizaciones es una preocupación contemporánea que se ha gestado en la segunda mitad del siglo XX. Sin embargo, ha cobrado mayor auge en los últimos veinte años, con la aparición de instrumentos y guías que permiten a los directivos de las organizaciones entender con mayor claridad cómo estos conceptos, que buscan el desarrollo sostenible y el bienestar común, pueden ser plasmados en términos tangibles y concretos en sus prácticas de gestión. En la actualidad, los esfuerzos llevados a cabo por parte de organismos internacionales, regionales y nacionales, que promueven el tema, y por un sector significativo de gremios y asociaciones empresariales se han orientado hacia el desarrollo de principios, instrumentos e indicadores de gestión y medición del impacto de las prácticas responsables, con el fin de guiar a las organizaciones en su adopción. Thompson y Driver (2005) destacan, en este sentido, el importante papel que estos instrumentos desempeñan como regulaciones voluntarias que se están convirtiendo, de manera gradual, en patrones generalizados ${ }^{1}$ y que, como sugiere Carroll (2004), es imperativo que sean adoptados por un número cada vez mayor de empresas.

En efecto, los instrumentos internacionales de los que hoy dispone la empresa para guiar su actuación, abordan propuestas para los distintos ámbitos de la RSE. En este sentido, una revisión de los mismos permite tener una visión general de los principales temas que hoy preocupan a la empresa en su gestión responsable. Según ello, como afirman Bondy et al. (2008), se pueden identificar dos tipos de organizaciones que participan en la generación de instrumentos: un primer grupo, que desarrolla principios básicos y generales para el correcto comportamiento de las organizaciones y, un segundo grupo, que toma estos principios y elabora instrumentos que buscan apoyar la implementación de la RSE.

Clasificación de los principales instrumentos existentes en la actualidad

Gran parte de los principales instrumentos disponibles comparten algunos aspectos en común: refuerzan la importancia de gestionar a todos los grupos de interés de la empresa, tienen un enfoque voluntario y un alcance global o nacional en su aplicación ${ }^{2}$. En lo que se refiere a los enfoques voluntarios para la adopción de la RSE, Fombrum (2005), Pérez Domínguez (2005), la Comisión Europea (2003) y GRI (2002) han clasificado los instrumentos con cierto nivel de coincidencia, según se muestra en el cuadro 1.

- Los principios generales y los códigos de conducta

En los últimos años, diversas iniciativas internacionales -como el Pacto Global, La Carta de la Tierra, la Agenda 21, Los Objetivos de Desarrollo del Milenio, promovidas por las Naciones Unidas; los principios y declaraciones de la Organización Internacional del Trabajo (OIT); los principios de gobierno corporativo propuestos por la Organización para la Cooperación y Desarrollo Económico (OCDE); el Libro Verde de la Unión Europea; los principios del comportamiento responsable y sostenible propuestos por el Sigma Project;

1. Thompson y Driver (2005) alertan sobre el hecho de que no necesariamente los instrumentos internacionales son aplicables en todos los contextos, pues existen muchos países que se encuentran en etapas menos avanzadas de la implementación de la RSE. Esto ha llevado a que en diversos países se trabajen versiones nacionales basadas en los instrumentos de alcance global, con ciertas adaptaciones que responden a las realidades propias de cada medio.

2. Es importante destacar que, en algunos países, la preparación de informes sociales se ha convertido en un requerimiento legal. Si bien en cada caso la regulación establece parámetros diferentes para definir qué empresas deben emitir los informes y cómo hacerlo, se observa un creciente interés en las entidades gubernamentales en este sentido. A modo de ejemplo, podemos citar el caso pionero de Francia, país que legisló a este respecto en 1997 
Cuadro 1

Propuestas para la clasificación de los instrumentos que abordan temas de RSE

\begin{tabular}{|c|c|c|c|c|}
\hline Enfoques abordados & $\begin{array}{l}\text { Fombrum } \\
(2005)\end{array}$ & $\begin{array}{l}\text { Pérez Domínguez } \\
\text { (2005) }\end{array}$ & $\begin{array}{c}\text { Comisión Europea } \\
\text { (2003) }\end{array}$ & $\begin{array}{c}\text { GRI } \\
(2002)\end{array}$ \\
\hline Principios generales & Códigos de conducta. & $\begin{array}{l}\text { Declaración de } \\
\text { principios, códigos de } \\
\text { conducta o buenas } \\
\text { prácticas. }\end{array}$ & $\begin{array}{l}\text { Principios } \\
\text { aspiracionales y } \\
\text { códigos de conducta. }\end{array}$ & $\begin{array}{l}\text { Códigos y } \\
\text { principios. }\end{array}$ \\
\hline $\begin{array}{l}\text { Estándares y guías } \\
\text { generales y } \\
\text { específicos para la } \\
\text { gestión de la RSE }\end{array}$ & $\begin{array}{l}\text { Estándares y } \\
\text { certificaciones } \\
\text { internacionales. } \\
\text { Lineamientos para la } \\
\text { gestión responsable } \\
\text { adaptados en el nivel } \\
\text { nacional. }\end{array}$ & $\begin{array}{l}\text { Directrices sobre } \\
\text { sistemas de gestión e } \\
\text { instrumentos de } \\
\text { certificación. }\end{array}$ & $\begin{array}{l}\text { Lineamientos para los } \\
\text { sistemas de gestión y } \\
\text { certificaciones. }\end{array}$ & $\begin{array}{l}\text { Estándares y } \\
\text { herramientas de } \\
\text { gestión. } \\
\text { Estándares } \\
\text { especializados en } \\
\text { el desempeño. }\end{array}$ \\
\hline Estándares para la & $\begin{array}{l}\text { Premios nacionales al } \\
\text { desempeño } \\
\text { responsable de las } \\
\text { empresas. }\end{array}$ & Índices de valor. & $\begin{array}{l}\text { Índices para la } \\
\text { inversión social } \\
\text { responsable. }\end{array}$ & $\begin{array}{l}\text { Informes de } \\
\text { desempeño. }\end{array}$ \\
\hline $\begin{array}{l}\text { Estándares orientados } \\
\text { a la divulgación de la } \\
\text { información y/o a la } \\
\text { rendición de cuentas }\end{array}$ & $\begin{array}{l}\text { Lineamientos para el } \\
\text { reporte. }\end{array}$ & $\begin{array}{l}\text { Marcos o estructuras } \\
\text { de información sobre } \\
\text { la RSE. }\end{array}$ & $\begin{array}{l}\text { Marcos para el reporte } \\
\text { y la rendición de } \\
\text { cuentas. }\end{array}$ & $\begin{array}{l}\text { Compromiso con } \\
\text { la rendición de } \\
\text { cuentas. }\end{array}$ \\
\hline
\end{tabular}

Elaboración propia.

entre varios otros- han buscado comprometer a las empresas con el respeto de los derechos humanos, con el comportamiento ético y con la sostenibilidad del planeta.

De acuerdo con Bondy et al. (2008), una de las razones por las que las empresas adoptan estos principios generales en sus códigos de comportamiento corporativos es mostrar su compromiso, tanto con grupos de interés internos como con grupos externos cercanos, y con la sociedad en su conjunto. Según afirman estos autores, en el caso de los códigos de conducta, que buscan la aplicación de principios generales de comportamiento, su uso se explica por la necesidad de proteger el espacio de la empresa en el mercado -influido por la reputación que de esta se tengay por el interés de que el comportamiento corpo- rativo sea consistente en el nivel global. Estas intenciones y pronunciamientos generales se han traducido, de manera gradual, en prácticas de gestión que guían la toma de decisiones de las empresas y que han hecho posible el surgimiento de otras iniciativas, relacionadas de manera más directa con la gestión empresarial, que se analizan a continuación.

- Estándares y guías generales para la gestión de la RSE

Algunos instrumentos disponibles ponen mayor énfasis en el cálculo de indicadores de gestión de las prácticas responsables, con miras a la realización de una autoevaluación al interior de la organización. En efecto, este énfasis en la generación de informes como medio de ges- 
tión y de comparación con otras organizaciones, y no solo como medio de información a la comunidad, amplía los usos potenciales de este instrumento. Este es el caso del instrumento propuesto por el Social Venture Network, para los Estados Unidos y Europa, y de diversos instrumentos desarrollados en la región de Latinoamérica: Instituto Ethos, de Brasil; IARSE, de Argentina; Acción Empresaria, de Chile; CentraRSE, de Guatemala; Deres, de Uruguay y Perú 2021, de Perú.

En el anexo 1 se describen las principales características de estos instrumentos. A diferencia de otros estándares propuestos, los instrumentos antes mencionados son de carácter amplio y recorren tres temas claves en la gestión responsable: el tema social, el tema laboral y el tema ambiental. La mayoría de estos estándares abordan, además, temas como el comportamiento ético de la empresa, prácticas de gobierno corporativo, prácticas de rendición de cuentas, el enfoque dado a los productos y servicios que la organización ofrece y algunos datos generales sobre su desempeño financiero. En el caso de los indicadores propuestos por el Instituto Ethos de Empresas y Responsabilidad Social (2006) de Brasil, el instrumento se presenta bajo la forma de un cuestionario en el que se plantean buenas prácticas en cada ámbito y se incluye una escala con diversos grados de desempeño, de forma que la organización autoevalúe su gestión y, en caso lo desee, pueda remitir sus resultados al Instituto Ethos para compararse con las estadísticas sobre desempeños observados en las empresas de más alto rendimiento en cada tópico o área de la responsabilidad social. Este instrumento y la metodología descrita han sido utilizados como referencia para la mayor parte de propuestas presentadas en el nivel regional.

- Estándares y guías vinculados a aspectos específicos de la RSE

Una de las familias de estándares de calidad más utilizadas es la ISO (International Organization for Standardization). La familia de normas ISO es bastante amplia y variada en su contenido. Para nuestros fines, en la actualidad, las normas más relevantes son: la serie 14000 y la serie $9000^{3}$. En el ámbito de las condiciones laborales, dos son las normas internacionales más reconocidas: la norma SA80004, inspirada en los derechos humanos y en las buenas prácticas de la gestión de personas, y las normas OHSAS 1800, más acotadas, pues están referidas específicamente al tema de la salud y seguridad ocupacional.

En el anexo 2 se presenta las iniciativas de carácter específico más conocidas en el medio y que se han constituido, por su aceptación y por el elevado prestigio de las instituciones creadoras, en estándares y normas de carácter internacional.

- Estándares para la evaluación del desempeño

En este grupo se incluyen, principalmente, aquellos sistemas de evaluación del desempeño que definen el perfil del comportamiento de las empresas con la finalidad de guiar a los inversionistas que optan por los fondos de inversión responsable o inversión ética. García Echevarría (1991: 10) ha destacado la importancia del movimiento de los fondos de inversión éticos debido a que promueven la «ética con rentabilidad». Como refieren Schwalb y

3. La ISO 26000 no ha sido analizada porque, a la fecha de elaboración de este artículo, estaba próxima a ser lanzada públicamente.

4. Destacada por diversos autores; entre ellos, Carrasco (2007), Schwalb y García (2004) y Waddock et al. (2004). 
García (2004), las inversiones socialmente responsables establecen un puente entre la rentabilidad, los principios y los valores morales. Por ello, quienes desarrollan este tipo de índices centran su análisis en la evaluación del desempeño corporativo en el tema de la responsabilidad social. Esto permite dar mayores elementos de decisión a aquellos inversionistas que ubican este criterio entre sus principales prioridades a la hora de decidirse por la mejor mezcla de productos financieros en su cartera de inversión.

La existencia de estos fondos de inversión no es reciente. De acuerdo con Hill et al. (2003), los fondos de inversión responsable cobraron mayor visibilidad en varios momentos de la historia: en la década de los años 1940, debido a las prácticas laborales injustas denunciadas por las agencias de gobierno y los sindicatos; en la década de los años 1070, como consecuencia de la guerra de Vietnam, el Apartheid y las luchas urbanas en Norteamérica; y, recientemente, con la mayor conciencia por el tema medioambiental.

Sobre los índices disponibles, Carrasco (2007) destaca la importancia del FSTE4Good y del Dow Jones Sustainability Index, como dos de las principales iniciativas desarrolladas en este contexto; mientras que Spiller (2000) afirma que el Domini Index constituye la guía más actual y comprehensiva sobre inversión ética en Norteamérica. Los cuatro índices se describen en el anexo 3. Si bien cada uno de estos índices tiene un radio de influencia y utilización determinado, en el proceso de evaluación comparten varios criterios comunes.

- Estándares y sistemas orientados a la divulgación de la información y/o a la rendición de cuentas

Doane y Holder (2007) han resaltado la importancia de los procesos de reporte y rendición de cuentas, sobre todo en el contexto de un mundo globalizado. Entre los principales ins- trumentos referidos al tema, destacan tres: la Guía para la elaboración de memorias de sostenibilidad del Global Reporting Initiative (GRI, 2006); el «balance social», en sus varias versiones, y el «estándar AA1000», norma que guía a las organizaciones para llevar a cabo un buen proceso de rendición de cuentas.

Los primeros reportes sociales hacen referencia al balance social. De acuerdo con Secchi (2007), el uso de estos instrumentos se inició en los Estados Unidos durante la década de los años 1960. Según Arizkuren (2002: 20):

[...] el balance social como método de medición de la responsabilidad social de la empresa, trata de definir ante qué agentes es responsable la empresa respecto a las áreas de interés social que se consideren oportunas $\mathrm{y}$, sobre todo, debe tratar de medir el grado de consecución de los objetivos marcados por la empresa para cada una de esas áreas sociales ante cada agente social.

Si bien no se trata de un balance en el sentido contable, para García Echevarría (1991) refleja cuáles han sido las aportaciones positivas y negativas de la empresa en esa sociedad.

En cuanto al informe de sostenibilidad, es relevante destacar algunas características centrales de este tipo de medio de divulgación de información, promovido por Global Reporting Initiative (GRI 2002):

o GRI usa el término «informe de sostenibilidad» como sinónimo de «informe de ciudadanía corporativa», «informe social»o «informe de la triple línea básica», refiriéndose al análisis de resultados económicos, sociales y ambientales.

- La rápida expansión de los lineamientos de GRI como instrumento de divulgación de información indica la fuerte tendencia a la rendición de cuentas y al desarrollo de redes con los agentes sociales, como prácticas empresariales claves. En efecto, un ele- 
mento fundamental del enfoque de GRI es que el proceso promueva la participación de los agentes sociales.

- GRI promueve la comparación en el desempeño de las empresas, por lo que facilita la evaluación del desempeño de la organización en función de los estándares y códigos existentes para cada aspecto.

- En relación con lo que no son los lineamientos GRI: no son un sistema de gestión, no son un estándar de desempeño y no son códigos de conducta.

- El sistema no propone la realización de una auditoría externa, más bien, está orientado a la evaluación interna de la política de sostenibilidad de la empresa y de los logros alcanzados.

Las principales características de los cuatro instrumentos reseñados en esta sección se muestran en el anexo 4.

Tras una revisión detallada de la información contenida en estos documentos, es posible observar diferencias sustantivas entre ellos. Al respecto, algunos tratadistas utilizan en forma indistinta el término «balance social», «informe social» e «informe de sostenibilidad» para hacer referencia a este instrumento. Sin embargo, en la mayor parte de los casos, el balance social se refiere básicamente a la relación de la empresa con sus trabajadores y con otros actores sociales; mientras que el informe de sostenibilidad alude a los componentes del triple resultado: desempeño económico, social y medioambiental.

Perera (2003) destaca la necesidad de integrar, de mejor manera, el análisis del impacto económico de la gestión responsable a la información financiera tradicional. Desde su planteamiento, resulta crucial que las organizaciones, que llevan a cabo iniciativas o programas dirigidos a sus grupos de interés, reflejen esta actividad en informes de carácter financiero, que muestren el flujo de generación de valor para la empresa y para aquellos a quienes destina sus recursos. Su propuesta rescata los intentos, iniciados en los años 1980 en los Estados Unidos, por establecer un cuerpo convincente de criterios técnicos que pongan a la contabilidad social en un plano de mayor preponderancia en la generación de instrumentos de medición de la responsabilidad social. Este autor propone el desarrollo de un cuarto estado financiero, orientado a reportar sobre la dimensión social de las empresas. Según sugiere, este informe financiero debiera mostrar cómo se distribuye el valor agregado generado por la operación entre los diversos grupos de interés, mediante la aplicación de los principios contables relevantes. El esquema de balance social propuesto por Deres (1999) incorpora este enfoque en la estructura de su documento.

Análisis comparativo de las variables incluidas en los principales instrumentos de medición

La revisión de los instrumentos descritos anteriormente permite identificar un conjunto de ámbitos de la actuación social responsable de la empresa y, asimismo, permite clasificar diversas acciones e iniciativas contenidas en estos documentos como parte del campo de acción de cada ámbito. Resulta pertinente enunciar algunos aspectos generales relevantes, identificados a partir de la revisión de los instrumentos:

- Varios de los instrumentos solicitan, como punto de partida, información referida al perfil de la organización.

- Son ocho los principales ámbitos o temas de la gestión responsable desarrollados entre el conjunto de instrumentos estudiados: el enfoque o la posición ética de la organización, el gobierno corporativo, la rendición de cuentas, la gestión medioambiental, la gestión social, la gestión laboral, la gestión económica, y la gestión de los productos y servicios ofrecidos. 
- No todos los instrumentos desarrollan todos estos ámbitos de la gestión responsable. Aquellos que abordan temas medioambientales enfocan la gestión responsable como el medio por el cual la organización puede contribuir al desarrollo sostenible.

- Entre los ocho elementos mencionados, los más abundantes en cuanto variables para el análisis son los temas ambiental, social y laboral. Por otra parte, sobre los dos últimos encontramos mayores puntos de coincidencia entre los diversos instrumentos.

- El gobierno corporativo y la rendición de cuentas cobran relevancia en diversos instrumentos.

- Los valores éticos, los códigos de conducta y los principios organizacionales pueden ser ubicados como los cimientos sobre los que se construye la organización. Sin un sólido enfoque de respeto a los principios básicos de la ética, difícilmente podremos estar hablando de RSE.

- Los aspectos económicos son los menos tocados en la evaluación del desempeño de la gestión responsable. Al parecer, hay todavía un camino importante que recorrer para el desarrollo de variables e indicadores de gestión vinculados a este tema. En todo caso, el enfoque que recibe este ámbito de la gestión en los instrumentos analizados está orientado a la identificación del valor socioeconómico generado a partir del comportamiento corporativo responsable.

- Un factor recurrente en cada uno de los ámbitos de análisis es la necesidad de que la organización desarrolle, al menos, tres elementos centrales en cada campo:

- Políticas específicas sobre la problemática a tratar, orientadas a apoyar la misión, visión y estrategia de la empresa. o Sistemas de gestión que aseguren su eficacia.

o Mecanismos de evaluación, monitorización e informe de los distintos grupos de interés de la organización.

- No todas las variables son aplicables a todas las organizaciones y sectores económicos. Será necesario elegir y adaptar aquellas que resultan centrales en el desempeño de la organización en estudio, pues, de otro modo, el instrumento de medición puede resultar lejano a la realidad que vive la empresa en su actividad diaria.

Principales temas contenidos en los instrumentos

- El ámbito laboral

Como propone Deres (2004), en este rubro deberían estar incluidas las políticas de recursos humanos que afectan a los empleados. En este sentido, CentraRSE (2008: 5) asocia el comportamiento responsable con el público interno con «[...] condiciones óptimas y adecuadas en términos laborales, para lograr mayor productividad y desarrollo personal. También incluye las relaciones y gobernabilidad interna de los accionistas y de los colaboradores a todo nivel organizacional». Un factor particular, observado en las propuestas más recientes sobre el tema, destaca la relevancia de las relaciones que la empresa desarrolla con el propio trabajador y de aquellas que promueve con su familia. En este sentido, complementa los aspectos de la vida laboral y la definición de estándares para lograr una óptima situación de empleo con acciones que mejoran la vida personal del trabajador (Canessa y Cuba 2006). Por otra parte, Social Venture Network sugiere como elemento adicional a las prácticas de gestión de recursos humanos, la consideración de la diversidad y del empoderamiento que la empresa debe dar a sus trabajadores, como dos ele- 
mentos importantes que deben delinear los principios de la gestión laboral (Goodwell 1996).

\section{- El ámbito social}

Tal como lo define CentraRSE (2008: 6), el ámbito social está referido a

[...] la búsqueda del desarrollo y superación de las comunidades inmediatas en donde opera la empresa y donde tenga intereses comerciales. Esta relación debe estar basada en una contribución y responsabilidad compartida, ya que es una relación ganar-ganar para ambas partes logrando así un desarrollo sostenible, reforzando la reputación de la empresa y logrando confianza por parte de la comunidad.

A propósito de este tema y en el mismo sentido, el Libro Verde destaca la responsabilidad social de las empresas, abarca la integración de esta en su entorno local, contribuyendo al desarrollo de las comunidades en que se insertan y gestionando el impacto que genera su presencia (sobre todo en las comunidades locales, pues dependen de la prosperidad de las mismas) (Comisión de las Comunidades Europeas, 2001). Para el Instituto Ethos, será necesario que se desarrollen proyectos de inversión social. Esta organización define este concepto como «[...] el repase voluntario de recursos privados, en forma planeada, monitorizada y sistemática para proyectos sociales, ambientales y culturales de interés público» (Instituto Ethos 2006: 78).

- El ámbito medioambiental

Desde la perspectiva de Deres (2004: 8), la responsabilidad medioambiental en el ámbito corporativo puede ser entendida como el «[...] compromiso de la organización empresarial con el medio ambiente y el desarrollo sustentable». Al respecto, CentraRSE complementa esta idea, precisando el posible rol de la empresa a partir de su quehacer cotidiano. En este sentido, considera que la acción responsable en el campo medioambiental estará referida al «[...] respeto y cuidado del entorno natural, en la forma como se hacen negocios, logrando un uso sostenible de insumos, reduciendo emisiones y residuos, generando mayor eficiencia, y produciendo más con menos» (CentraRSE 2008: 5).

- El ámbito de la transparencia, los valores y el gobierno corporativo

Acción Empresarial (2001) afirma que la ética empresarial se refiere a cómo una compañía integra el conjunto de valores (honestidad, confianza, respeto, justicia y otros) en sus propias políticas, prácticas y en la toma de decisiones en todos los niveles de la empresa. Deres (2004) agrega que estos principios deberán orientar la definición de los objetivos estratégicos de la empresa.

En lo que se refiere al gobierno corporativo y a la transparencia, la OCDE (2004) propone un conjunto de elementos para sentar las bases de lo que constituye el buen gobierno corporativo empresarial (la preservación de los derechos y el tratamiento equitativo de los accionistas, la definición de las funciones claves en el ámbito de la propiedad, la definición del papel de las agentes sociales o partes interesadas en el gobierno de la empresa, la revelación de datos y la transparencia de información, y la definición de las responsabilidades del consejo de administración).

Para Social Venture Network, un adecuado gobierno corporativo deberá balancear los intereses de empleados, clientes, inversionistas, acreedores, proveedores, las comunidades afectadas y otros agentes sociales relacionados con los objetivos estratégicos y con la operación del negocio. Estas prácticas, según afirman, fortalecen el capital financiero y el capital humano de la empresa (Goodwell 1996). 
- El ámbito de la oferta de productos y servicios al mercado

De acuerdo con GRI (2006), este ámbito de la RSE pone énfasis en la empresa como ofertante de sus productos y servicios al mercado, y resalta, además, la responsabilidad que tiene en su rol como informadora de los atributos de dicha oferta. Para Social Venture Network, la actuación empresarial en este campo tendrá que estar inspirada en un compromiso con la integridad, la seguridad y la satisfacción del cliente (Goodwell 1996).

En este sentido, el Libro Verde menciona la búsqueda de relaciones duraderas con clientes mediante una oferta que se base en la comprensión de sus deseos (Comisión de las Comunidades Europeas 2001). CentraRSE (2008), por su parte, precisa algo más las grandes líneas de acción empresarial en este campo, destacando la importancia de ofrecer un mejor servicio; la necesidad de asegurar la claridad en las transacciones comerciales; una orientación permanente hacia la mejora de los productos y hacia el cumplimiento de estándares de calidad; así como, el desarrollo de prácticas de mercadeo responsable y adecuadas a las exigencias del mercado.

- El ámbito de la gestión de la cadena de suministro

En torno a este tema, Acción Empresarial (2001) resalta la importancia de mantener adecuadas relaciones entre la empresa y su cadena de valor, donde todos los participantes ac- túan de manera sistémica. En este sentido, propone que se tenga presente que toda empresa desarrolla una serie de etapas, relacionadas entre sí, en el proceso de creación de productos y servicios. Según sostiene, las partes que constituyen una cadena de valor son interdependientes, de modo que el cambio de una de ellas impacta a las demás.

Al respecto, el Libro Verde se refiere a la necesidad de colaborar de manera estrecha con los socios comerciales para reducir la complejidad y los costos, y para aumentar la calidad. En este sentido, al igual que varias otras instituciones, como GRI (2006), resalta la importancia del respeto de los derechos humanos de las personas involucradas en estas transacciones (Comisión de las Comunidades Europeas 2001). Como propone Perú 2021, el respeto por los derechos humanos -aludido antes- se ve reflejado en el modo en que la empresa evalúa y selecciona a estos socios comerciales, así como en la forma en que transfiere recursos para contribuir en su desarrollo, inculcando en ellos valores (Canessa y Cuba 2006). A esto se agrega la necesidad de que la empresa ejerza un rol educativo y articulador, promoviendo la gestión social responsable en la cadena de suministro (Goodwell 1996).

En el cuadro 2 se presenta una síntesis de los principales tópicos abordados por cada ámbito de la RSE. Si bien este listado no pretende ser exhaustivo, sí busca ofrecer una perspectiva general sobre los tópicos o las acciones que de manera recurrente han sido citados en la literatura disponible sobre el tema 
Un instrumento de medida para conocer las tendencias de los directivos en la priorización de las acciones de Responsabilidad Social Empresarial (RSE)

Cuadro 2

Principales elementos presentados en los instrumentos internacionales sobre RSE

\begin{tabular}{|c|c|}
\hline ÁMBITO MEDIOAMBIENTAL & ÉTICA Y VALORES \\
\hline $\begin{array}{l}\text { Políticas de conservación del me-dioabiente, siste- } \\
\text { mas de gestión ambiental y desarrollo de proyectos } \\
\text { y programas. }\end{array}$ & $\begin{array}{l}\text { Código de ética, políticas y sistemas para atención } \\
\text { y defensa de aspectos relacionados con los dere- } \\
\text { chos humanos (en la empresa y en la cadena de } \\
\text { suministro). }\end{array}$ \\
\hline Criterios para la utilización de energía. & Benchmarking ético. \\
\hline Criterios para la utilización de agua. & Recompensa por defensa de temas éticos. \\
\hline $\begin{array}{l}\text { Criterios para la utilización de combustibles fósiles } \\
\text { y otros combustibles. }\end{array}$ & $\begin{array}{l}\text { Sistemas documentados de monit-orización, eva- } \\
\text { luación y reporte de aspectos éticos y/o existencia } \\
\text { de comité ético. }\end{array}$ \\
\hline $\begin{array}{l}\text { Utilización de materiales o materias primas con cri- } \\
\text { terio ecológico. }\end{array}$ & Política de no discriminación. \\
\hline Utilización de hábitats con biodiver-sidad. & Libertad de asociación y negociación. \\
\hline $\begin{array}{l}\text { Control de emisiones y fluidos y/o derrames signifi- } \\
\text { cativos. }\end{array}$ & Trabajo infantil. \\
\hline $\begin{array}{l}\text { Evaluación del impacto ambiental de productos y de } \\
\text { operaciones de la empresa (incluye evaluación de la } \\
\text { ecoefi-ciencia y el uso de tecnologías apropiadas). }\end{array}$ & Trabajo forzado \\
\hline Recojo de productos al término de ciclo de vida. & Uso de armas y uso de la fuerza. \\
\hline $\begin{array}{l}\text { Proyectos de reciclaje y control y eliminación de } \\
\text { residuos. }\end{array}$ & Defensa de los derechos de los nativos. \\
\hline $\begin{array}{l}\text { Atención de reclamos por temas me-dioambientales y } \\
\text { registro de incidentes por incumplimientos de normas. }\end{array}$ & Educación ética. \\
\hline Gestión del transporte. & Mecanismos de discusión de dilemas éticos. \\
\hline $\begin{array}{l}\text { Criterios ambientales en la selección de proveedo- } \\
\text { res y otros socios del negocio. }\end{array}$ & Honestidad en sus pronunciamientos. \\
\hline $\begin{array}{l}\text { Política de comunicación del desempeñoambien- } \\
\text { tal. }\end{array}$ & Trato a animales. \\
\hline $\begin{array}{l}\text { Iniciativas de capacitación medioam-biental al in- } \\
\text { terior y hacia fuera. }\end{array}$ & Prácticas disciplinarias. \\
\hline
\end{tabular}


Un instrumento de medida para conocer las tendencias de los directivos en la priorización de las acciones de Responsabilidad Social Empresarial (RSE)

(Continuación)

\begin{tabular}{|c|c|c|}
\hline ÁMBITO SOCIAL & $\begin{array}{l}\text { ÁMBITO DE LA GESTIÓN DE } \\
\text { LA CADENA DE SUMINISTRO }\end{array}$ & $\begin{array}{l}\text { ÁMBITO DE LA OFERTA DE } \\
\text { PRODUCTOS Y SERVICIOS AL } \\
\text { MERCADO }\end{array}$ \\
\hline $\begin{array}{l}\text { Políticas y estrategias para gestio- } \\
\text { nar impacto en comunidades y de- } \\
\text { sarrollo local. }\end{array}$ & $\begin{array}{l}\text { Criterios sociales y ambientales } \\
\text { considerados en la evaluación de } \\
\text { la relación con socios. }\end{array}$ & $\begin{array}{l}\text { Información sobre el producto y/ } \\
\text { o políticas de etiquetado. }\end{array}$ \\
\hline $\begin{array}{l}\text { Programas de filantropía o de in- } \\
\text { versión social para comunidad lo- } \\
\text { cal. }\end{array}$ & $\begin{array}{l}\text { Información transparente a ca- } \\
\text { nales de la cadena de suminis- } \\
\text { tro. }\end{array}$ & $\begin{array}{l}\text { Compromiso con la calidad de la } \\
\text { producción. }\end{array}$ \\
\hline Liderazgo e influencia social. & $\begin{array}{l}\text { Cumplimiento, respeto a dere- } \\
\text { chos de proveedores. }\end{array}$ & Servicio de atención al cliente. \\
\hline $\begin{array}{l}\text { Contratación de trabajadores pro- } \\
\text { venientes de la comunidad local. }\end{array}$ & $\begin{array}{l}\text { Consulta sobre satisfacción de } \\
\text { la cadena de suministro. }\end{array}$ & $\begin{array}{l}\text { Honor a garantías y/o reclamos } \\
\text { de clientes. }\end{array}$ \\
\hline $\begin{array}{l}\text { Cumplimiento de obligaciones con } \\
\text { el sector público. }\end{array}$ & $\begin{array}{l}\text { Medición de criterios sociales en } \\
\text { proveedores, distribuidores y } \\
\text { contratistas. }\end{array}$ & $\begin{array}{l}\text { Políticas y sistemas de gestión y } \\
\text { monitorización para preservación } \\
\text { de la salud y seguridad del con- } \\
\text { sumidor. }\end{array}$ \\
\hline $\begin{array}{l}\text { Participación en proyectos y/o cam- } \\
\text { pañas de bien público. }\end{array}$ & $\begin{array}{l}\text { Datos del perfil de proveedores y } \\
\text { canales de distribución. }\end{array}$ & $\begin{array}{l}\text { Respeto a la privacidad del clien- } \\
\text { te y otros grupos de interés. }\end{array}$ \\
\hline $\begin{array}{l}\text { Participación de trabajadores en } \\
\text { enti-dades de gobierno local y enti- } \\
\text { dades comunales. }\end{array}$ & $\begin{array}{l}\text { Prácticas de comercio justo y } \\
\text { apoyo al desarrollo de competen- } \\
\text { cias en los proveedores (incluye } \\
\text { capacitación en prácticas res- } \\
\text { ponsables). }\end{array}$ & $\begin{array}{l}\text { Política de publicidad y promo- } \\
\text { ción honesta. }\end{array}$ \\
\hline $\begin{array}{l}\text { Incorporación de empleados en } \\
\text { prácticas filantrópicas. }\end{array}$ & $\begin{array}{l}\text { Cumplimiento con compromisos } \\
\text { con acreedores. }\end{array}$ & $\begin{array}{l}\text { Consideraciones de impacto am- } \\
\text { biental en el diseño de produc- } \\
\text { tos, servicios y procesos. }\end{array}$ \\
\hline $\begin{array}{l}\text { Incorporación de clientes y otras } \\
\text { empresas y actores sociales en } \\
\text { prácticas filantrópicas o de desa- } \\
\text { rrollo comunal. }\end{array}$ & & $\begin{array}{l}\text { Gestión de la relación con el } \\
\text { cliente (CRM). }\end{array}$ \\
\hline $\begin{array}{l}\text { Políticas para la gestión de la con- } \\
\text { tribución en materia política. }\end{array}$ & & $\begin{array}{l}\text { Contribuición a la sociedad con } \\
\text { nuevos productos y servicios (in- } \\
\text { novación). }\end{array}$ \\
\hline $\begin{array}{l}\text { Mecanismos de comunicación de } \\
\text { doble vía con la comunidad. }\end{array}$ & & $\begin{array}{l}\text { Relaciones de alianza con com- } \\
\text { petidores. }\end{array}$ \\
\hline $\begin{array}{l}\text { Relación con medios de comunica- } \\
\text { ción, gremios, centros educativos y } \\
\text { otras organizaciones sociales. }\end{array}$ & & $\begin{array}{l}\text { Políticas en torno a tema de pre- } \\
\text { cios y competencia leal. }\end{array}$ \\
\hline
\end{tabular}

(Continúa) 
(Continuación)

\begin{tabular}{|c|c|}
\hline ÁMBITO DE LA GESTIÓN DE PERSONAL & ÁMBITO DEL GOBIERNO CORPORATIVO \\
\hline Demografía del personal. & $\begin{array}{l}\text { Estructura organizativa establecida para temas de responsa- } \\
\text { bilidad social y ética. }\end{array}$ \\
\hline $\begin{array}{l}\text { Definición de políticas laborales, indicadores y medi- } \\
\text { ción de satisfacción laboral. }\end{array}$ & Sistemas de gobierno corporativo explícitos. \\
\hline $\begin{array}{l}\text { Proceso de comunicación externa de políticas y sistemas } \\
\text { de verificación y registro. }\end{array}$ & Procesos de planeamiento estratégico. \\
\hline Servicios a pensionistas y jubilados. & Gestión e involucramiento de agentes sociales. \\
\hline $\begin{array}{l}\text { Rotación de personal y política de estabilidad en el } \\
\text { empleo. }\end{array}$ & Políticas y sistemas sobre la gestión de la RSE. \\
\hline Jornada laboral, carga de trabajo y ausentismo. & $\begin{array}{l}\text { Gestión de la relación con los inversores y comunicación de } \\
\text { información. }\end{array}$ \\
\hline $\begin{array}{l}\text { Política remunerativa explícita con participación de uti- } \\
\text { lidades y planes de beneficio justos. }\end{array}$ & Consideraciones sobre la gestión de crisis y riesgos. \\
\hline $\begin{array}{l}\text { Gestión de relaciones laborales (negociación sindical y } \\
\text { derechos de afiliación). }\end{array}$ & $\begin{array}{l}\text { Rol del directorio en el respeto de derechos de accionistas y } \\
\text { otros grupos de interés, así como en el respeto a principios y } \\
\text { valores organizacionales. }\end{array}$ \\
\hline $\begin{array}{l}\text { Atención de otras necesidades personales y familiares de } \\
\text { los trabajadores (balance vida-trabajo, salud en el nivel } \\
\text { general, seguros, etcétera). }\end{array}$ & Alto directivo involucrado en relaciones con la comunidad. \\
\hline $\begin{array}{l}\text { Seguridad y salud ocupacional y registro de accidentes } \\
\text { de trabajo. }\end{array}$ & Procesos de evaluación de altos mandos. \\
\hline Vivienda y/o alimentación y/o transporte. & Mecanismos de consulta al interior de la organización. \\
\hline $\begin{array}{l}\text { Sistemas de información y comunicación sistemática con } \\
\text { trabajadores. }\end{array}$ & Procesos justos de toma de decisiones. \\
\hline $\begin{array}{l}\text { Trato equitativo a minorías y sistemas de igualdad de } \\
\text { oportunidades (valor por la diversidad). }\end{array}$ & Valores inmersos en la cultura organizacional. \\
\hline $\begin{array}{l}\text { Procesos de captación y selección del equipo humano } \\
\text { responsables. }\end{array}$ & $\begin{array}{l}\text { Mecanismos para el aprendizaje organizacional, gestión del } \\
\text { conocimiento e innovación. }\end{array}$ \\
\hline Desarrollo del personal y línea de carrera. & $\begin{array}{l}\text { Compromiso con estándares internacionales en el campo am- } \\
\text { biental, laboral y social. }\end{array}$ \\
\hline Condiciones de contratación y calidad de contratos. & $\begin{array}{l}\text { Sistemas de información al directorio sobre efectos de la ope- } \\
\text { ración, los productos y servicios. }\end{array}$ \\
\hline Capacitación, entrenamiento y tutoría. & Composición de alta dirección y directorio. \\
\hline Asignación de ahorros medioambientales a trabajadores. & Alta dirección accesible. \\
\hline Política de retención del personal. & Políticas en torno a corrupción y soborno. \\
\hline Programas de desvinculación. & Proceso de monitoreo y auditoria. \\
\hline \multirow[t]{4}{*}{ Participación de trabajadores en el gobierno corporativo. } & $\begin{array}{l}\text { Reporte y políticas de información a los agentes sociales (re- } \\
\text { porte social y/o reporte de sostenibilidad). }\end{array}$ \\
\hline & $\begin{array}{l}\text { Reporte de políticas y desempeño en tema de derechos hu- } \\
\text { manos. }\end{array}$ \\
\hline & $\begin{array}{l}\text { Integración de sistemas de rendición de cuentas a sistemas } \\
\text { organizativos de planificación y registro. }\end{array}$ \\
\hline & Proyección de resultados. \\
\hline
\end{tabular}

Elaboración propia. 
La necesidad de integrar los instrumentos de RSE

Entre los principales esfuerzos por estudiar el abanico de instrumentos existentes relacionados con diversos aspectos de la gestión de la RSE, destaca el trabajo llevado a cabo por Sigma Project, que se centró en la elaboración de sus propios lineamientos para la gestión responsable (Instituto Ethos 2004b). Asimismo, resalta el estudio realizado por la Comisión Europea (2003). Esta última organización elaboró un mapeo de instrumentos e iniciativas que permite ofrecer una visión general de los grandes temas abordados, pero sin entrar en detalle sobre las acciones e indicadores contemplados en cada caso. En efecto, el mapeo realizado por esta organización identifica ámbitos desarrollados en los instrumentos y está dirigido a la concienciación de las empresas en torno a los temas de RSE. A partir de su trabajo, se identificaron cinco ámbitos de actuación responsable: políticas sobre el lugar de trabajo, política medioambiental, política de mercado, política social y valores de la empresa.

Como menciona Waddock (2004), el reto a futuro es lograr la generación de un sistema que combine y racionalice los diversos instrumentos disponibles en la actualidad. Según refiere Arizkuren (2002), se han producido numerosas investigaciones en relación con la medición de la responsabilidad social. Desde la perspectiva de la autora, esta proliferación de documentos nos muestra una tendencia clara hacia la necesidad de confluir en la definición de criterios uniformes y de aplicación mundial, de modo que se potencie la capacidad de comparación de los mecanismos de divulgación de información y que se adopte una visión integradora, incorporándolos como instrumentos de sistemas más amplios de gestión.

Según el Instituto Ethos (2004b), diversos académicos y hombres de negocios demandan la integración de los sistemas de gestión organizativos y los marcos de trabajo de la RSE, como paso necesario hacia el desarrollo sostenible. En este sentido, la publicación de la Norma ISO 26000 promete integrar las acciones de RSE a la lógica de la gestión de excelencia en las organizaciones ${ }^{5}$.

Como menciona la Comisión Europea (2003), si bien el enfoque segmentado del análisis de instrumentos sobre RSE es útil para quienes operan en cada contexto particular, no ofrece una visión amplia de lo realizado a la fecha. Esto último, así como la ausencia en la literatura académica especializada de propuestas que integren instrumentos previos, deja espacio a la construcción de escalas de medida validadas estadísticamente para la investigación en el campo de la gestión empresarial responsable, tal como la que propone el presente artículo.

Construcción de un instrumento para la priorización de las acciones de RSE

Identificación de ámbitos de la RSE

Para llevar a cabo el proceso de construcción de un instrumento que permita explorar la forma en que quienes protagonizan la gestión de la RSE priorizan los distintos ámbitos de la actuación responsable de la empresa, se han revisado 17 instrumentos internacionales que abordan el tema, ya sea con un enfoque amplio de acciones y ám-

5. De acuerdo con el Comité ISO 26000 sobre RSC, la norma es de naturaleza voluntaria, no incluye requisitos para su aplicación y no será certificable. Se trata de que esta norma se aplique en empresas públicas y privadas de países desarrollados y en desarrollo. Entre sus principales atributos destaca el proceso participativo de elaboración de la misma, con la finalidad de llegar a un consenso sobre el concepto de RSE y los temas relevantes. Asimismo, resalta el hecho de que busca ser una guía para traducir los principios generales en acciones, mediante la inclusión de buenas prácticas documentadas. Esta iniciativa tiene como propósito aprovechar los aportes previos sobre el tema en diversas culturas, sociedades y entornos (ISO Committtee 2004 y <www.iso26000peru.org >). 
bitos de la RSE, como con un enfoque más específico, dependiendo del objetivo del instrumento y de su posible utilidad. Es necesario recalcar que esta revisión no pretende ser exhaustiva. Sin embargo, ha tratado de abarcar los principales instrumentos reconocidos en el ámbito internacional y ha puesto un énfasis mayor en el análisis de los instrumentos desarrollados en la región de los países latinoamericanos.

A partir de esta información, se han identificado seis posibles ámbitos de la actuación social responsable de la empresa:

- El ámbito laboral: se incluyen aquellas acciones que la empresa realiza en favor del bienestar y desarrollo profesional y personal de su equipo humano ${ }^{6}$, así como para la mejora de la calidad de vida de sus familias.

- El ámbito social: se incluyen aquellas acciones que la empresa desarrolla como ciudadana corporativa (miembro de la sociedad) para contribuir con el bienestar y la mejora de la calidad de vida de las comunidades en las que opera y de la sociedad en su conjunto.

- El ámbito medioambiental: se incluyen aquellas acciones que la empresa desarrolla en el ámbito de la gestión ambiental, minimizando el posible impacto de sus operaciones, desarrollando una conciencia ecológica y preservando el ambiente y los recursos naturales.

- El ámbito de la transparencia, los valores y el gobierno corporativo: se incluyen aquellas acciones referidas a la forma en que la empresa integra un conjunto de principios éticos y de buen gobierno en la toma de decisiones, en la definición de sus objetivos estratégicos y en la dirección de la compañía, considerando los derechos y las responsabilidades con los diversos grupos de interés con los que interactúa.

- El ámbito de la oferta de productos y servicios al mercado: se incluyen aquellas acciones que la empresa desarrolla en el diseño, la comunicación y la oferta de sus productos y servicios, así como en la gestión de sus relaciones con los clientes y/o consumidores.

- El ámbito de la gestión de la cadena de suministro: se incluyen aquellas acciones que la empresa desarrolla en la gestión de sus relaciones con sus socios comerciales, entre ellos: proveedores, intermediarios, agentes y socios estratégicos que actúan en el sector.

Selección de acciones específicas de cada ámbito de la RSE

Con la finalidad de llevar a cabo el proceso de selección de los ítems por incluir, se siguieron los siguientes pasos: se realizó la revisión y listado del conjunto de acciones encontradas en los instrumentos disponibles para la gestión, evaluación y reporte en el tema de la RSE, y se agruparon estas acciones por temas o ámbitos de la RSE. Las acciones que correspondían a un proceso que pudiese ser definido de manera más amplia se expresaron en enunciados que las abarcaran; así, se redujo el número inicial de acciones listadas. Se revisaron por segunda vez las acciones contenidas en cada ámbito, contrastándolas con el listado amplio que se formuló en un inicio, de tal forma que las seleccionadas representaran adecuadamente las prácticas empresariales en cada caso. Asimismo, se procuró asegurar una buena cobertura temática y un equilibrio en el número de acciones presentadas en cada ámbito de la $\mathrm{RSE}$, de manera que el instrumento no indujera al entrevistado a priorizar un ámbito frente al resto por la importancia relativa mostrada en el cuestionario.

Dos criterios específicos adicionales fueron utilizados para seleccionar las acciones finalmente incluidas en el modelo de instrumento: que se incluyeran prácticas propias de cada ámbito de

6. La referencia al equipo humano de la empresa incluye a todas las formas de contratación de mano de obra para el desarrollo de la actividad empresarial. 
la RSE -habitualmente desarrolladas por las empresas a partir de programas específicos- y que se incluyera un segundo grupo de prácticas que hiciera referencia a procesos centrales de gestión (Karapetrovic y Jonke 2003), usualmente desarrollados por las empresas e incluidos en los instrumentos revisados. Sobre este último grupo de prácticas se definió que estos procesos fueran contemplados en cada ámbito de la RSE, para evidenciar en qué casos eran privilegiados y en qué otros casos eran menos valorados. A partir de la definición de los ítems contenidos en el instrumento, a cada uno de los 100 directivos incluidos en la muestra se le pidió puntuar-mediante una escala de Likert de 5 puntos- el nivel de prioridad otorgado a cada una de las acciones de RSE propuestas.

Análisis de la fiabilidad del instrumento de medición

- La muestra

Con la finalidad de validar el instrumento de medida propuesto, este fue aplicado a una muestra de directivos que protagonizan la toma de decisiones en temas de RSE en 100 de las 200 empresas más grandes del Perú. Para seleccionar a los directivos entrevistados se utilizó un muestreo aleatorio sin reposición, considerando como estratos dos tipos de sectores de actividad empresarial: un primer grupo conformado por las empresas de los sectores extractivo, industrial y de construcción que, en el Perú, tienen un impacto significativo en el medioambiente y en las comunidades donde llevan a cabo sus programas de RSE -lo que las convierte en un grupo de empresas con alta exposición frente a los agentes socia- les y sus expectativas-; y un segundo grupo de organizaciones pertenecientes a los sectores comercial y de servicios, con menor exposición pública y con un relativo menor impacto directo en las comunidades y el medioambiente. En el caso de una muestra de 100 observaciones, para un Alpha de 0,05, la potencia de la muestra para encontrar un efecto moderado resultó ser de $94 \%$; es decir, adecuada. Esta muestra de empresas constituye un 6,93\% de error en el muestreo aleatorio simple sin reposición.

- La escala de medida

Con el fin de conocer las opiniones del encuestado sobre la prioridad que otorga al conjunto de ámbitos de la RSE en estudio, cada directivo fue sometido a la valoración de un total de 78 ítems o preguntas. Este conjunto de preguntas constituye lo que en la literatura se denomina como una escala aditiva de medida.

- Análisis factorial - fiabilidad y validez del instrumento

La comprobación de la fiabilidad del instrumento construido se realizó mediante un análisis factorial, que permitió valorar empíricamente la dimensionalidad del conjunto de ítems propuestos. Bajo la lógica descrita, en una escala aditiva de medida, los ítems incluidos debieran presentar cargas elevadas en un determinado factor o dimensión. Como paso previo al análisis factorial, las variables fueron sometidas a un conjunto de pruebas que permitieron justificar este procedimiento, haciendo presumible la correlación entre las variables incluidas $^{7}$.

7. Las pruebas realizadas fueron:

- La matriz de correlaciones y el determinante: el determinante de la matriz de correlaciones entre variables resultante fue de 2,98 E-0412, un número bastante próximo a 0 , por lo que da indicios de la pertinencia del análisis factorial.

- KMO y la prueba de esfericidad de Bartlett: se obtuvo una medida de adecuación muestral KMO de 0,754.

- Diagonal de la matriz anti-imagen: la mínima calificación obtenida fue 0,623 , oscilando la mayor parte de los valores obtenidos entre 0,7 y 0,8 . 
Finalmente, mediante el análisis factorial se obtuvo una solución con 6 factores y 72 ítems que explicaban el $60,66 \%$ de la varianza total. En esta solución, las cargas factoriales de los ítems fueron superiores a 0,40. Cabe anotar que los ítems presentaron su máxima carga factorial en uno de estos 6 factores, que representaron adecuadamente los 6 ámbitos de la RSE recogidos de la revisión de la literatura existente ${ }^{8}$.

La unidimensionalidad de cada una de las seis subescalas se probó con un análisis factorial confirmatorio, que demostró que, para cada una de ellas, el primer factor explicaba mucha más varianza que el segundo y, de manera sucesiva, este más que el siguiente. Como se aprecia en los cuadros presentados en el anexo 5 , la fiabilidad o consistencia interna de cada una de las subescalas que conforman las dimensiones del constructo quedó comprobada al obtener coeficientes Alpha de Cronbach superiores a 0,80 en todas ellas; así como correlaciones ítem-total de, al menos, 0,40 en todos sus ítems. Por otra parte, como se observa en el anexo 6 , se procedió a verificar la validez divergente o capacidad discriminante de las escalas. Para ello se constató que no existieran correlaciones estadísticamente significativas entre una escala y cada una de las otras; de este modo, se encontró que las escalas miden elementos diferentes. La validez convergente no pudo realizarse porque no se contó con un instrumento alternativo, provisto por la literatura, para llevar a cabo esta prueba.

En el cuadro 3 se muestra el Alpha de Cronbach obtenido para la solución factorial final.

Cuadro 3

Prioridad en la actuación social responsable: Alpha de Cronbach para la solución factorial

\begin{tabular}{|l|l|c|c|}
\hline $\begin{array}{c}\text { Equivalente } \\
\text { en análisis } \\
\text { factorial }\end{array}$ & $\begin{array}{c}\text { Ámbitos de la actuación social responsable según } \\
\text { el modelo de investigación }\end{array}$ & $\begin{array}{c}\text { Alpha de Cronbach } \\
\text { a partir del análisis } \\
\text { factorial }\end{array}$ & $\begin{array}{c}\text { Alpha de Cronbach a } \\
\text { partir de las escalas } \\
\text { aditivas }\end{array}$ \\
\hline Factor 1 & Prioridad en el ámbito medioambiental & 0,955 & 0,959 \\
\hline Factor 2 & Prioridad en el ámbito laboral & 0,917 & 0,912 \\
\hline Factor 3 & Prioridad en el ámbito social & 0,939 & 0,925 \\
\hline Factor 4 & $\begin{array}{l}\text { Prioridad en el ámbito de la gestión de la } \\
\text { cadena de suministro }\end{array}$ & 0,922 & 0,921 \\
\hline Factor 5 & $\begin{array}{l}\text { Prioridad en el ámbito de la transparencia, los } \\
\text { valores y el gobierno corporativo }\end{array}$ & 0,913 & 0,905 \\
\hline Factor 6 & $\begin{array}{l}\text { Prioridad en el ámbito de la oferta de productos } \\
\text { y servicios al mercado }\end{array}$ & 0,863 & 0,812 \\
\hline \multirow{2}{*}{ GENERAL } & Alpha Cronbach General & 0,970 & 0,968 \\
\cline { 2 - 4 } & Número de variables & 72 & 78 \\
\hline
\end{tabular}

Elaboración propia.

8. Del análisis de los factores y su composición, es necesario destacar que la priorización de las acciones de RSE por parte del directivo estuvo medida a partir de 78 variables, un número significativamente alto para ser sometido a pruebas de validación estadística en el ámbito de las ciencias sociales. De ese total, el modelo factorial descrito ha recogido satisfactoriamente a 72 variables, con solo seis reclasificaciones de variables entre los ámbitos predefinidos en el modelo de investigación. 
Análisis de los resultados obtenidos

Como se puede observar en el cuadro 4 , los directivos encuestados, en promedio, otorgaron las puntuaciones más elevadas a tres aspectos habitualmente centrales de la gestión organizacional y tradicionalmente más vinculados con el negocio: la oferta de productos y servicios al mercado, la gestión laboral, y las acciones vinculadas a la gestión transparente, los valores y el gobierno corporativo. En este primer grupo, el tercero de estos ámbitos de acción obtuvo la mayor dispersión en las respuestas, frente a una mayor concentración en las puntuaciones obtenidas por las acciones referidas a la oferta de productos o servicios al mercado.

En contraposición, los ámbitos ubicados por debajo del promedio de la prioridad general otorgada por los encuestados fueron los referidos a la gestión de la cadena de suministro, la gestión medioambiental y la gestión social. Nótese la mayor dispersión generada en las respuestas de los encuestados al ser preguntados por las acciones medioambientales y sociales, lo cual indica la existencia de visiones diversas sobre la prioridad que debiera otorgarse a estos temas en el nivel corporativo.
Una mirada a la priorización realizada por los directivos sobre las acciones propuestas en cada ámbito de la actuación social responsable permitirá conocer, con mayor profundidad, la opinión de los encuestados. Las puntuaciones medias por acción se presentan en los cuadros del anexo 5 .

En cuanto a la oferta de productos y servicios al mercado, se evidencia la importancia atribuida por los directivos al desarrollo de acciones puntuales que generan un efecto directo en la sensación de satisfacción del cliente frente al producto ofrecido. Según ello, recibe la mayor puntuación el tema de la preservación de la seguridad y privacidad del cliente, tópico sensible en el Perú por la inestabilidad vivida en décadas anteriores, de convulsión social, en las que la preservación de la información del cliente constituía un asunto de vital importancia. A continuación, se puntúa más alto el cumplimiento de condiciones pactadas y la inversión en la mejora del producto y del servicio, aspectos directamente asociados con la calidad de la oferta. El siguiente bloque de acciones se encuentra más asociado a prácticas internas de gestión, dejando en último lugar a las acciones de promoción y publicidad honesta. Respecto de la distribución observada en la escala de puntuación, en este caso es notoria la tenden-

Cuadro 4

Prioridad en la actuación social responsable: media y desviación estándar

\begin{tabular}{|l|c|c|}
\hline \multicolumn{1}{|c|}{ Prioridad en la actuación social responsable } & Media & Desviación estándar \\
\hline $\begin{array}{l}\text { Prioridad del ámbito de la oferta de productos y } \\
\text { servicios }\end{array}$ & 4,659 & 0,497 \\
\hline Prioridad del ámbito laboral & 4,207 & 0,648 \\
\hline $\begin{array}{l}\text { Prioridad del ámbito de la transparencia, los } \\
\text { valores y el gobierno corporativo }\end{array}$ & 4,104 & 0,785 \\
\hline $\begin{array}{l}\text { Prioridad del ámbito de la gestión de la cadena de } \\
\text { suministros }\end{array}$ & 3,898 & 0,787 \\
\hline Prioridad del ámbito medioambiental & 3,649 & 1,022 \\
\hline Prioridad del ámbito social & 3,595 & 0,940 \\
\hline
\end{tabular}

Elaboración propia. 
cia a asignar la máxima puntuación a estos tópicos, con una frecuencia de respuesta muy por encima de los siguientes niveles de puntuación.

En lo que se refiere a la priorización de las acciones en el ámbito de la gestión laboral, se puede observar que el primer lugar en las prioridades del grupo lo ocupa el cumplimiento de las obligaciones con el Estado. Cabe mencionar que este ítem fue concebido, en un inicio, con un enfoque amplio de cumplimiento corporativo con todo tipo de obligaciones con el ente regulador; sin embargo, su asociación con este ámbito y su alto nivel de puntuación podrían dar a entender que los directivos consideran al cumplimiento de la normatividad laboral como una de sus principales preocupaciones en relación con el Estado. Tras este elemento, destaca la priorización a aspectos de carácter básico en la práctica laboral empresarial contemporánea realizada por los directivos. En este sentido, se ha otorgado mayor prioridad al respeto de derechos elementales de los trabajadores y se dejó en posiciones bastante menos importantes prácticas más modernas de gestión laboral, como son el desarrollo de sistemas de información, la implementación de programas de retención del talento, la rendición de cuentas ante públicos internos y externos sobre las prácticas laborales y la adopción de estándares laborales de carácter internacional, tema que queda rezagado al último lugar.

Por otra parte, resultan destacables dos acciones en particular. Por un lado, llama la atención la posición por debajo del promedio del ítem referido a la consulta a los trabajadores sobre su satisfacción con la empresa, práctica recomendada entre los expertos en temas laborales para promover el buen clima laboral. Por otra parte, resalta la importancia atribuida a la rendición de cuentas a públicos internos sobre aspectos vinculados con el producto y el servicio al cliente. Este hecho estaría llamando la atención sobre la percepción que los directivos tienen en relación con la importancia de mantener al personal informado sobre aspectos íntimamente vinculados con el negocio.

Siguiendo el orden de prioridad general de cada ámbito, corresponde analizar las puntuaciones otorgadas a los ítems correspondientes a la transparencia, los valores y el gobierno corporativo. En este caso, es posible observar que la mayor prioridad es atribuida al desarrollo de códigos de ética, tema que es especialmente sensible en la mayoría de países de Latinoamérica. A continuación, resalta la percepción de los directivos en torno a la necesidad de insertar en los procesos de planificación de la empresa temas relacionados con el buen gobierno y con el comportamiento transparente, basado en valores corporativos; así como su correlato en la asignación de recursos, adopción de estándares internacionales -bastante relevantes en este ámbito en particular- y el desarrollo de sistemas de monitorización.

Finalmente, también destaca la colocación en las últimas posiciones de dos acciones vinculadas con la evaluación de desempeño. La primera, relacionada con la evaluación del desempeño de los directores y la alta gerencia, práctica poco observada en el medio; y la segunda acción, referida a la promoción, mediante los sistemas de incentivos al personal, de una buena gestión de las relaciones con los grupos de interés o stakeholders. En cuanto a la distribución de las puntuaciones, resalta una mayor frecuencia en la asignación de la máxima puntuación al tema de la utilización de códigos de ética, frente al resto de puntajes que se encuentran, en general, más cercanos entre sí en la preferencia de los encuestados.

Respecto de la priorización de acciones vinculadas con la gestión de la cadena de suministro, como en el caso de las prácticas de gestión laboral, se evidencia que las principales preocupaciones del grupo de directivos están asociadas al

9. La micro y pequeña empresa constituyen alrededor del $98 \%$ del empresariado nacional. 
cumplimiento de condiciones mínimas en la relación con los agentes que participan en la cadena de suministro. En este sentido, el énfasis ha sido puesto en la búsqueda de transparencia en la comunicación de las condiciones contractuales, así como en la preocupación por el desarrollo de condiciones justas en el trato a estos grupos.

Tras este primer grupo de prácticas puntuales consideradas prioritarias, a continuación, se ubica el conjunto de acciones vinculadas con la necesidad de insertar en los sistemas de gestión de la empresa temas relacionados con la cadena de suministro. Por otra parte, los resultados muestran la poca prioridad relativa otorgada por los encuestados a la posibilidad de invertir en el desarrollo de competencias de los participantes en la cadena de suministro, de manera que estos puedan adoptar prácticas socialmente responsables. Asimismo, se valora poco la utilización de criterios sociales en sus procesos de selección de proveedores, distribuidores, agentes o socios comerciales. Finalmente, cabe destacar el menor interés mostrado por la consulta realizada a los socios y agentes comerciales de la empresa sobre su satisfacción con esta última, lo que puede ser explicado por la relación asimétrica que en muchos casos existe entre las grandes empresas y sus compañías proveedoras, de considerable menor dimensión.

En lo que se refiere al ámbito de la gestión medioambiental, los directivos otorgan la mayor puntuación promedio a la adopción de estándares y sistemas internacionales que buscan promover procesos de calidad en la oferta de productos y servicios al mercado. Esto es lógico en un entorno como el peruano, en donde la convivencia con los recursos naturales es significativa y, por ello, la conciencia sobre los efectos de las operaciones de la empresa es cada vez más visible. También destaca la alta prioridad otorgada al desarrollo de canales de diálogo con los grupos de interés. Tras estos dos ítems, un conjunto de acciones orientadas a los procesos de gestión de la empresa de los temas medioambientales recibe la atención de los directivos. En las últimas posiciones, por el contrario, se ubican aquellas acciones que van más allá de las operaciones de la empresa y que proponen que las compañías desempeñen un papel más activo en la promoción del tema medioambiental en la sociedad y con los agentes sociales con los que interactúan. Estas acciones, más discrecionales, en general, han sido menos valoradas por los directivos encuestados.

El último grupo de ítems analizados corresponde al ámbito de la gestión de temas sociales, es decir, aquellos íntimamente vinculados con la acción de la empresa en la comunidad y en la sociedad en su conjunto. Resulta curioso que la mayor puntuación obtenida en este grupo de variables se otorgue al cumplimiento de los compromisos contraídos con los proveedores, intermediarios, agentes y socios comerciales. Este ítem podría haber estado asociado de manera más directa al ámbito de la gestión de la cadena de suministro; sin embargo, en la realidad latinoamericana, uno de los impactos sociales más visibles de las grandes empresas es su capacidad para contribuir al desarrollo de la pequeña y microempresa local ${ }^{9}$. En este sentido, se explica la asociación que realizan los directivos entre este tema y las prácticas sociales corporativas.

Otro aspecto que recibió una puntuación relativa superior fue el desarrollo de proyectos de inversión social, también fuertemente asociado con la búsqueda del desarrollo local. Como en algunos casos anteriores, en orden de prioridad, los tópicos asociados con la implementación y gestión de las iniciativas al interior de la empresa, en la búsqueda de eficiencia en su desempeño, constituyen un segundo grupo de acciones. Finalmente, por debajo del promedio del ámbito en estudio, se ubican las acciones relacionadas con el involucramiento de más grupos de interés en sus programas sociales o la vocación de las empresas por participar en órganos de la sociedad civil. Es importante comentar que las cifras muestran que existe desconocimiento en cuanto a la existencia de estándares o referencias internacionales para mejorar el desempeño de los programas sociales. 


\section{Conclusiones}

La revisión de la literatura existente permitió evidenciar la ausencia de propuestas que integren instrumentos previos relacionados con la gestión de la RSE. En este sentido, el presente artículo busca contribuir a la construcción de una escala de medida validada estadísticamente para la investigación en el campo de la gestión empresarial responsable.

El aporte de un instrumento como el propuesto, para conocer la forma en que los directivos priorizan los diversos ámbitos de la actuación responsable en la empresa, puede ser útil tanto para quienes estudian el fenómeno de la incorporación de la RSE en el modelo de negocios empresarial -desde el mundo de la investigación académica-, como para aquellos actores de la sociedad que buscan promover e impulsar el desempeño responsable en el nivel corporativo. Esto debido a que puede permitir un mayor conocimiento sobre la forma en que los directivos priorizan las diversas posibles acciones de RSE y, así, dejar traslucir cuáles son los ámbitos donde se pone mayor énfasis en la empresa y cuáles son aquellos otros que aún no han sido interiorizados como relevantes en el desempeño corporativo.

Por otra parte, mediante el uso de un instrumento de priorización de posibles acciones de RSE como el que se propone, será posible llevar a cabo estudios que perfilen y comparen diversos subsegmentos de directivos y empresas en cuanto a su valoración de la RSE. Esto, con miras a lograr una mayor comprensión del efecto de ciertas variables del entorno y del perfil del directivo que pudieran estar afectando la visión que se tenga sobre el tema. En ese sentido, será posible comparar valoraciones realizadas por directivos de distintos sectores de actividad empresarial, de regiones o zonas geográficas con diverso grado de desarrollo, de diverso tamaño y dimensión de la firma, o de aquellas con mayor o menor influencia de capitales extranjeros en la estructura de propiedad y en la cultura organizacional, entre varios muchos otros criterios de análisis. Asimismo, será posible analizar si factores personales del perfil del directivo pudieran estar influyendo en la forma en que percibe y prioriza la actuación responsable en el nivel corporativo.

En el mundo académico, el proceso de toma de decisiones del directivo continúa siendo un foco central de atención. Conocer estos procesos mentales podría ayudar a desarrollar incentivos efectivos y mecanismos que faciliten la acción empresarial en lo que se refiere a su interacción con los diversos grupos de interés. Por ello, este instrumento -validado estadísticamente- podría ser utilizado en cualquier estudio que tenga como objetivo analizar con rigurosidad académica los factores que influyen en el proceso de toma de decisiones en temas de RSE, ya sea mediante la búsqueda de correlaciones entre variables relevantes o de relaciones de causalidad que expliquen los diversos grados de implementación de las prácticas responsables en la empresa moderna. Quedará, por lo tanto, en el juicio de quienes utilicen esta herramienta la oportunidad para diagnosticar realidades y proponer acciones de mejora que permitan avanzar en la implementación generalizada de comportamientos corporativos responsables.

Por supuesto, aún queda espacio para perfeccionar el instrumento de medida propuesto, en los ítems contenidos en cada sección. Esto podrá hacerse mediante una mayor profundización en el estudio de la literatura especializada sobre cada uno de los ámbitos de la RSE, los cuales por otra parte responden a una dinámica cambiante, en función de la evolución de las expectativas y demandas de la sociedad en la que la empresa actúa. Asimismo, de encontrarse en el futuro un instrumento alternativo -con un enfoque integral de los ámbitos de decisión en materia de RSE-, será relevante realizar las comparaciones necesarias para reforzar la validez de esta propuesta. Finalmente, a partir del lanzamiento de la ISO 26000 , se genera el reto de incluir aquellas acciones o ítems que esta nueva propuesta pueda aportar. 


\section{Referencias}

\section{ACCIÓN EMPRESARIAL}

2001 Indicadores acción empresarial de responsabilidad social. Santiago de Chile: Acción Empresarial.

Arizkuren, A.

2002 Manual de realización del balance social en la empresa. San Sebastián: ESTE-Universidad de Deusto.

\section{BLOWFIELD, M. y J. G. FRYNAS}

2005 «Setting New Agendas: Critical Perspectives on Corporate Social Responsibility in the Developing World». En: International Affairs, vol. 81, N³, pp. 499-513.

BONDY, K.; D. MATTEN y J. MOON

2008 «Multinational Corporation Codes of Conduct: Governance Tools for Corporate Social Responsibility». En: Corporate Governance: An International Review, vol. 16, $\mathrm{N}^{\circ} 4$, pp. 294-311.

CANESSA, G. y C. M. CUBA

2006 Indicadores de RSE. Lima, Perú: 2021.

CARRASCO, I.

2007 «Corporate Social Responsibility, Values and Cooperation». En: International Advances in Economic Research, vol. 13, N ${ }^{\circ} 4$, pp. 454460.

Carroll, A. B.

2004 «Managing Ethically with Global Stakeholders: A Present and Future Challenge». En: Academy of Management Executive, vol. 18, $\mathrm{N}^{\circ} 2$, pp. 114-120.

\section{CENTRARSE}

2008 IndicaRSE. Indicadores de responsabilidad social empresarial. Guatemala: CentraRSE.

CONFEDERACIÓN DE LA PEQUEÑA Y MEDIANA EMPRESA ARAGONESA - CEPYME-ARAGON

2003 «Sistemas de gestión de la prevención de riesgos laborales según norma OHSAS 18001:
1999». En: Procedimientos basados en las normas OSHAS 18000 para su implantación en pymes del subsector fabricación de productos metálicos. Proyecto CEPYME Aragón. Fecha de consulta: 05/06/2006. <www.conectapyme.com/files/publica/ OHSAS_Anexo_2.pdf>.

\section{COMISIÓN DE LAS COMUNIDADES EUROPEAS}

2001 Libro verde. Fomentar un marco europeo para la responsabilidad social de las empresas. Bruselas: Comisión de las Comunidades Europeas.

\section{COMISIÓN EUROPEA}

2003 Mapping Instruments for Corporate Social Responsibility. Luxemburgo: Comisión Europea.

CONFEDERACIÓN NACIONAL DE INSTITUCIONES EMPRESARIALES PRIVADAS DEL PERÚ -CONFIEP y ORGANIZACIÓN INTERNACIONAL DEL TRABAJO - OIT 1997 Manual de balance social. Lima: Confiep.

\section{DERES}

2004 Manual de autoevaluación. Responsabilidad social empresaria. Montevideo: Deres-Desarrollo de la Responsabilidad Social.

1999 Manual para la preparación e implementación del balance social en el Uruguay. Montevideo: Deres-Desarrollo de la Responsabilidad Social.

DOANE, D y A. HOLDER

2007 Why Corporate Social Responsibility is Failing Children. Londres: Corporate Responsibility Coalition y Save the Children.

DOW JONES SUSTAINABILITY INDEXES - DJSI Y WORLD INDEX DESIGN COMMITTEE

2004 Dow Jones Sustainability World Indexes Guide. Suiza: Dow Jones Indexes, STOXX Limited y SAM Group, versión 6.

Fernández, R.

2001 «Estrategia medioambiental, stakeholders y valores de los directivos: un análisis de su relación en las empresas manufactureras españolas». Tesis doctoral. Universidad de León. 
Fombrun, C. J.

2005 «Building Corporate Reputation Initiatives: Evolving Standards». En: Corporate Reputation Review, vol. 8, N¹, pp. 7-11.

FTSE. THE INDEX COMPANY

2003 FTSE4Good Index Series. Inclusion Criteria. Reino Unido: FTSE International Limited.

GARCÍA ECHEVARRÍA, S.

1991 Ética empresarial y comportamiento directivo. Cómo configurar corporaciones empresariales edificantes. Madrid: Instituto de Dirección y Organización de Empresas (IDOE), Universidad de Alcalá de Henares.

Global Reporting Initiative - GRI

2006 RG. Guía para la elaboración de memorias de sostenibilidad. Versión 3.0. Amsterdam: Global Reporting Initiative.

2002 Sustainability Reporting Guidelines. Boston: Global Reporting Initiative.

Goodwell, E.

1996 Standards of Corporate Social Responsibility. San Francisco: Social Venture Network.

HAMMER, B.

2004 Workshop series for Corporate Social Responsibility. Objectives and Agenda. Lima, Universidad del Pacífico.

HILL, R. P.; D. STEPHENS E I. SMITH

2003 «Corporate Social Responsibility: An Examination of Individual Firm Behavior». En: Business and Society Review, vol. 108, №3, pp. 339-364.

INSTITUTO ARGENTINO DE RESPONSABILIDAD SOCIAL EMPRESARIA - IARSE

2007 Guía de Autoaplicación. Indicadores de responsabilidad social empresaria. Edición 2007/ 2008. Córdoba: IARSE e Instituto Ethos de Empresas y Responsabilidad Social.

Instituto Ethos de Empresas y Responsabilidad Social 2006 Indicadores Ethos de responsabilidad social empresarial. Sao Paulo: Instituto Ethos de
Empresas y Responsabilidad Social.

2004a ETHOS Business Social Responsibility Indicators. $5^{\text {a }}$ ed. Sao Paulo: Ripasa.

2004b Tool Compatibility Guide 2004. Sao Paulo: Ethos Institute of Business and Social Responsibility/UniEthos.

Institute of Social and Ethical AccountAbility - ISEA 1999 AccountAbility 1000 (AA1000) Framework. Standards, Guidelines and Professional Qualification. Londres: ISEA.

\section{ISO COMMITTEE}

2004 «ISO Committee Makes Social Responsibility Recommendation». En: Business and the Environment with ISO 14000 Updates, vol. 15, $\mathrm{N}^{\circ} 6$, pp. 12-13.

KARAPETROVIC, S. y J. JONKE

2003 «Integrating of standardized management systems: searching for recipe and ingredients». En: Total Quality Management, vol. $14, \mathrm{~N}^{\circ} 4$, pp. 451-459.

ORGANIZACIÓN PARA LA COOPERACIÓN Y DESARROLLO ECONÓMICO - OCDE

2004 Principios de gobierno corporativo de la OCDE. Madrid: Ministerio de Economía y Hacienda.

PERERA, L.

2003 Un cuarto estado financiero sobre la dimensión social de las empresas. Santiago de Chile: PricewaterhouseCoopers.

\section{PÉREZ DOMÍNGUEZ, F.}

2005 «Instrumentos de la RSE: criterios de clasificación». Em: Observatorio sobre la Responsabilidad Social de la Empresa y Relaciones Laborales (Observatorio Laboral On-Line del CARL). Fecha de consulta: 31/12/2010. $<$ www.juntadeandalucia.es/.../INSTRUMENTOS\% 20DE\%20\%20LA\%20RSE.pdf>.

SCHWALB, M. M. y E. GARCÍA

2004 Instrumentos y normas para evaluar y medir la responsabilidad social empresarial. Lima: Centro de Investigación de la Universidad del Pacífico. 
Un instrumento de medida para conocer las tendencias de los directivos en la priorización de las acciones de Responsabilidad Social Empresarial (RSE)

SECCHI, D.

2007 «Utilitarian, Managerial and Relational Theories of Corporate Social Responsibility». En: International Journal of Management Review, vol. 9, N4, pp.347-373.

SOCIAL ACCOUNTABILITY INTERNATIONAL - SAI

2001 Responsabilidad social 8000. Nueva York: SAI.

SPILLER, R.

Páginas web

AccountAbility

Fecha de consulta: 05/06/2006.

$<w w w$.accountability.org.uk>.

Confederación de la Pequeña y Mediana Empresa Aragonesa (CEPYME-ARAGÓN)

Fecha de consulta: 05/06/2006.

$<$ www.conectapyme.com>.

2000 «Ethical Business and Investment: A Model for Business and Society». En: Journal of Business Ethics, vol. 7, N¹/2, pp. 149-160.

THOMPSON, G. y C. DRIVER

2005 «Stakeholder Champions: How to Internationalize the Corporate Social Responsibility Agenda». En: Business Ethics: A European Review, vol. 14, N 1, pp. 56-66.

WADDOCK, S.

2004 «Parallel Universes: Companies, Academics, and the Progress of Corporate Citizenship». En: Business and Society Review, vol. 109, N . 1, pp. 5-42.

Domini Social Investments

Fecha de consulta: 05/06/2006. <www.domini.com>.

Dow Jones Sustainability Indexes

Fecha de consulta: 05/06/2006.

$<w w w$.sustainability-indexes.com>.

Ethibel

Fecha de consulta: 05/06/2006. <www.ethibel.org>.

FTSE. The Index Company

Fecha de consulta: 05/06/2006. <www.ftse.com>.

ISO 14000. The ISO 14001 Informatipon Zone

Fecha de consulta: 05/06/2006. <www.iso.14001.org.uk>.

WADDOCK, S.; C. BODWELL y S. GRAVES

2003 «Responsabilidad: el nuevo imperativo empresarial». En: Revista de Empresa, № 4, pp. 1636.

\section{ISO 2006 Comité Perú}

Fecha de consulta: 22/11/2008. <www.iso26000 peru.org>. 


\section{Anexos}

Anexo 1

Estándares y guías generales para la gestión de la RSE

\begin{tabular}{|c|c|c|c|c|c|c|}
\hline & $\begin{array}{l}\text { Objetivo } \\
\text { central }\end{array}$ & $\begin{array}{l}\text { Institución } \\
\text { creadora del } \\
\text { instrumento }\end{array}$ & $\begin{array}{l}\text { Ambito de } \\
\text { acción }\end{array}$ & $\begin{array}{l}\text { Participantes } \\
\text { en la formación } \\
\text { del instrumento }\end{array}$ & Inicio & Uso \\
\hline $\begin{array}{l}\text { SOCIAL } \\
\text { VENTURE } \\
\text { NETWORK }\end{array}$ & $\begin{array}{l}\text { Desarrollar un es- } \\
\text { tándar o compendio } \\
\text { de estrategias y téc- } \\
\text { nicas para mejorar el } \\
\text { desempeño de la } \\
\text { empresa u organiza- } \\
\text { ción, en general, en } \\
\text { la gestión de la res- } \\
\text { ponsabilidad social. }\end{array}$ & $\begin{array}{l}\text { Social Venture } \\
\text { Network, organiza- } \\
\text { ción que agrupa a } \\
\text { una red de empren- } \\
\text { dedores de nego- } \\
\text { cios y emprende- } \\
\text { dores sociales de } \\
\text { Estados Unidos y } \\
\text { Europa. }\end{array}$ & $\begin{array}{l}\text { Provee de princi- } \\
\text { pios y estándares } \\
\text { relacionados con } \\
\text { las prácticas res- } \\
\text { ponsables. Evalúa } \\
\text { el desempeño de } \\
\text { las organizacio- } \\
\text { nes a partir de in- } \\
\text { dicado-res cualita- } \\
\text { tivos, cuantitativos } \\
\text { o monetarios, y su- } \\
\text { giere recursos o } \\
\text { herramientas para } \\
\text { la mejor gestión en } \\
\text { cada estándar. }\end{array}$ & $\begin{array}{l}\text { En la construcción } \\
\text { de los estándares } \\
\text { participaron cerca } \\
\text { de } 220 \text { pensado- } \\
\text { res, empresarios y } \\
\text { profesionales. }\end{array}$ & 1987 & $\begin{array}{l}\text { Permiten sugerin } \\
\text { prácticas y el uso } \\
\text { de recursos adicio- } \\
\text { nales para la mejo- } \\
\text { ra de las prácticas } \\
\text { socialmente res- } \\
\text { ponsables. }\end{array}$ \\
\hline $\begin{array}{l}\text { INDICADORES } \\
\text { ETHOS }\end{array}$ & $\begin{array}{l}\text { Servir como herra- } \\
\text { mienta de aprendi- } \\
\text { zaje y autoevalua- } \\
\text { ción para las empre- } \\
\text { sas, en el esfuerzo } \\
\text { por desarrollar prác- } \\
\text { ticas de negocios so- } \\
\text { cialmente responsa- } \\
\text { bles, en el diseño de } \\
\text { sus estrategias y en } \\
\text { el monitoreo de su } \\
\text { desempeño. }\end{array}$ & $\begin{array}{l}\text { Instituto Ethos y } \\
\text { UniEthos de Brasil. }\end{array}$ & $\begin{array}{l}\text { Presenta prácticas } \\
\text { responsables en } \\
\text { los campos social, } \\
\text { ambiental y labo- } \\
\text { ral, en las empre- } \\
\text { sas analizadas. }\end{array}$ & $\begin{array}{l}\text { Representantes } \\
\text { de asociados y de } \\
\text { empresas locales } \\
\text { en Brasil. }\end{array}$ & $\begin{array}{c}2000 \\
\text { Actualizado } \\
\text { anualmente }\end{array}$ & $\begin{array}{l}\text { Permiten el diag- } \\
\text { nóstico y la puntua- } \\
\text { ción del desempe- } \\
\text { ño de la organiza- } \\
\text { ción en los temas } \\
\text { mencionados. }\end{array}$ \\
\hline $\begin{array}{l}\text { INDICADORES } \\
\text { IARSE }\end{array}$ & $\begin{array}{l}\text { Constituirse en una } \\
\text { herramienta que } \\
\text { aporta a la incorpo- } \\
\text { ración de prácticas } \\
\text { de RSC en la planifi- } \\
\text { cación de estrate- } \\
\text { gias y la monito- } \\
\text { rización del desem- } \\
\text { peño general de la } \\
\text { empresa. }\end{array}$ & $\begin{array}{l}\text { Instituto Argentino } \\
\text { de Responsabili- } \\
\text { dad Social Empre- } \\
\text { saria (IARSE) de } \\
\text { Argentina. }\end{array}$ & $\begin{array}{l}\text { Proporciona un } \\
\text { conjunto de indica- } \\
\text { dores en } 7 \text { ámbitos } \\
\text { de la RSC (RSC in- } \\
\text { terna y externa). Se } \\
\text { incluyen indicado- } \\
\text { res referidos al ni- } \\
\text { vel de avance y se } \\
\text { propone el recojo } \\
\text { de información so- } \\
\text { bre indicadores } \\
\text { cuantitativos. }\end{array}$ & $\begin{array}{l}\text { Adapta a la reali- } \\
\text { dad argentina el } \\
\text { Manual de Indica- } \\
\text { dores de Respon- } \\
\text { sabilidad Social } \\
\text { Empresaria del Ins- } \\
\text { tituto Ethos de Bra- } \\
\text { sil. }\end{array}$ & $\begin{array}{c}2004 \\
\text { Actualizado } \\
\text { anualmente } \\
2001\end{array}$ & $\begin{array}{l}\text { Permiten el diag- } \\
\text { nóstico y la puntua- } \\
\text { ción del desempe- } \\
\text { ño de la organiza- } \\
\text { ción en los temas } \\
\text { mencionados. Se } \\
\text { trata de un instru- } \\
\text { mento de autoeva- } \\
\text { luación y aprendi- } \\
\text { zaje en el nivel in- } \\
\text { terno. }\end{array}$ \\
\hline $\begin{array}{l}\text { INDICADORES } \\
\text { ACCIÓN } \\
\text { EMPRESARIA }\end{array}$ & $\begin{array}{l}\text { Ser una herramien- } \\
\text { ta práctica para eva- } \\
\text { luar el grado de de- } \\
\text { sarrollo de estrate- } \\
\text { gias, políticas y prác- } \\
\text { ticas de RSC de un } \\
\text { buen ciudadano cor- } \\
\text { porativo. }\end{array}$ & $\begin{array}{l}\text { Acción Empresarial } \\
\text { de Chile }\end{array}$ & $\begin{array}{l}\text { Se presentan indi- } \\
\text { cadores cualitati- } \\
\text { vos y cuantitativos } \\
\text { para la evaluación } \\
\text { de políticas y accio- } \\
\text { nes de la empresa } \\
\text { en } 5 \text { ámbitos de la } \\
\text { RSC. }\end{array}$ & $\begin{array}{l}\text { Desarrollado por } \\
\text { Acción Empresarial } \\
\text { de Chile, con el } \\
\text { apoyo de la Funda- } \\
\text { ción Ford, y con la } \\
\text { asesoría técnica de } \\
\text { la Escuela de Admi- } \\
\text { nistración de la } \\
\text { Pontificia Universi- } \\
\text { dad Católica de } \\
\text { Chile. }\end{array}$ & & \begin{tabular}{|lr} 
Los indicadores \\
pueden ser utili- \\
zados para la auto- \\
evaluación y como \\
herramienta de \\
gestión y de pla- \\
neamiento.
\end{tabular} \\
\hline
\end{tabular}


Un instrumento de medida para conocer las tendencias de los directivos en la priorización de las acciones de Responsabilidad Social Empresarial (RSE)

(Continuación)

\begin{tabular}{|c|c|c|c|c|c|c|}
\hline & $\begin{array}{l}\text { Objetivo } \\
\text { central }\end{array}$ & $\begin{array}{l}\text { Institución } \\
\text { creadora del } \\
\text { instrumento }\end{array}$ & $\begin{array}{l}\text { Ambito de } \\
\text { acción }\end{array}$ & $\begin{array}{l}\text { Participantes } \\
\text { en la formación } \\
\text { del instrumento }\end{array}$ & Inicio & Uso \\
\hline INDICARSE & $\begin{array}{l}\text { Medir la aplicación } \\
\text { de políticas y prác- } \\
\text { ticas de RSC en } \\
\text { las empresas so- } \\
\text { cias y no socias } \\
\text { del Centro. }\end{array}$ & $\begin{array}{l}\text { Centro para la } \\
\text { Acción de la } \\
\text { Responsabilidad } \\
\text { S } 0 \text { c c i a } \\
\text { (CentraRSE) de } \\
\text { Guatemala. }\end{array}$ & $\begin{array}{l}\text { Se presentan indi- } \\
\text { cadores referidos a } \\
\text { prácticas y políticas } \\
\text { de RSC en } 7 \text { ejes } \\
\text { relacionados con } \\
\text { la RSC interna y } \\
\text { externa. } \\
\text { Utiliza } 4 \text { tipos de } \\
\text { preguntas: pregun- } \\
\text { tas que evalúan el } \\
\text { proceso de avance, } \\
\text { preguntas cuantita- } \\
\text { tivas, preguntas de } \\
\text { autodiagnóstico y } \\
\text { preguntas abiertas } \\
\text { para realizar co- } \\
\text { mentarios. }\end{array}$ & $\begin{array}{l}\text { Es un instrumen- } \\
\text { to de autoeva- } \\
\text { luación que se } \\
\text { basa en modelos } \\
\text { de indicadores in- } \\
\text { ternacionales lati- } \\
\text { noamericanos, } \\
\text { adaptados al con- } \\
\text { texto de Guate- } \\
\text { mala. }\end{array}$ & 1987 & $\begin{array}{l}\text { Facilita la auto- } \\
\text { evaluación en } \\
\text { cuanto a la ges- } \\
\text { tión empresarial, } \\
\text { puede ser utiliza- } \\
\text { do también como } \\
\text { listado de buenas } \\
\text { prácticas. }\end{array}$ \\
\hline $\begin{array}{l}\text { MANUAL DE } \\
\text { AUTOEVALUA- } \\
\text { CIÓN } \\
\text { DERES }\end{array}$ & $\begin{array}{l}\text { Convertirse en una } \\
\text { herramienta que fa- } \\
\text { cilita a las empre- } \\
\text { sas efectuar una } \\
\text { mirada introspec- } \\
\text { tiva sobre su pro- } \\
\text { pio desempeño en } \\
\text { las distintas áreas } \\
\text { de la RSC. }\end{array}$ & $\begin{array}{l}\text { Desarrollo de la } \\
\text { Responsabilidad } \\
\text { Social (Deres) de } \\
\text { Uruguay. }\end{array}$ & $\begin{array}{l}\text { Se presentan indi- } \\
\text { cadores cuantitati- } \\
\text { vos y cualitativos en } \\
5 \text { ámbitos de la RSC } \\
\text { (RSC interna y RSC } \\
\text { externa). }\end{array}$ & $\begin{array}{l}\text { Se basa en los } \\
\text { instrumentos de- } \\
\text { sarrollados por } \\
\text { Ethos y Acción } \\
\text { Empresarial. }\end{array}$ & 2004 & $\begin{array}{l}\text { Facilita la auto- } \\
\text { evaluación y pla- } \\
\text { nificación de } \\
\text { metas y objeti- } \\
\text { vos en los temas } \\
\text { de RSC. }\end{array}$ \\
\hline $\begin{array}{l}\text { INDICADORES } \\
\text { PERÚ } \\
2021\end{array}$ & $\begin{array}{l}\text { Ser una herramien- } \\
\text { ta práctica que per- } \\
\text { mita evaluar el gra- } \\
\text { do de integración de } \\
\text { la RSC en las es- } \\
\text { trategias, las políti- } \\
\text { cas y los procesos } \\
\text { de las empresas } \\
\text { peruanas. }\end{array}$ & $\begin{array}{l}\text { Perú } 2021 \text { en } \\
\text { Perú }\end{array}$ & $\begin{array}{l}\text { Se presentan indi- } \\
\text { cadores referidos a } \\
\text { prácticas y políticas } \\
\text { de RSC relaciona- } \\
\text { dos con } 7 \text { grupos de } \\
\text { agentes sociales. } \\
\text { Utiliza, principal- } \\
\text { mente, indicadores } \\
\text { cualitativos y sugie- } \\
\text { re el recojo de infor- } \\
\text { mación de un con- } \\
\text { junto de indicado- } \\
\text { res cuantitativos. }\end{array}$ & $\begin{array}{l}\text { Se basa en los } \\
\text { instrumentos de- } \\
\text { sarrollados por } \\
\text { Ethos, Deres, Ac- } \\
\text { ción Empresarial } \\
\text { e IndicaRSE. }\end{array}$ & 2006 & $\begin{array}{l}\text { Se constituye en } \\
\text { un diagnóstico } \\
\text { inicial de RS para } \\
\text { la empresa y } \\
\text { fuente de ideas } \\
\text { en su relación } \\
\text { con cada grupo } \\
\text { de agentes so- } \\
\text { ciales. }\end{array}$ \\
\hline
\end{tabular}

Elaboración propia, a partir de Acción Empresarial (2001), Canessa y Cuba (2006), CentraRSE (2008), Deres (2004), Goodwell (1996), IARSE (2007), Instituto Ethos (2004a y b). 
Anexo 2

Instrumentos que abordan temas de carácter específico

\begin{tabular}{|c|c|c|c|c|c|c|}
\hline & $\begin{array}{l}\text { Objetivo } \\
\text { central }\end{array}$ & $\begin{array}{l}\text { Institución } \\
\text { creadora del } \\
\text { instrumento }\end{array}$ & $\begin{array}{l}\text { Ambito de } \\
\text { acción }\end{array}$ & $\begin{array}{l}\text { Participantes } \\
\text { en la formación } \\
\text { del instrumento }\end{array}$ & Inicio & Uso \\
\hline $\begin{array}{l}\text { SERIE } \\
\text { ISO } 9000\end{array}$ & $\begin{array}{l}\text { Desarrollar estándares } \\
\text { internacionales que } \\
\text { permitan la gestión total } \\
\text { de calidad de los pro- } \\
\text { ductos o servicios ofre- } \\
\text { cidos y evitar los costos } \\
\text { de inspecciones finales, } \\
\text { garantías o reprocesos. }\end{array}$ & $\begin{array}{l}\text { Organización inter- } \\
\text { nacional para la } \\
\text { estandarización } \\
\text { (ISO, por sus siglas } \\
\text { en inglés) }\end{array}$ & $\begin{array}{l}\text { Provee criterios para } \\
\text { la gestión de calidad } \\
\text { de los procesos de } \\
\text { diseño, manufactura } \\
\text { y oferta de productos } \\
\text { y servicios. }\end{array}$ & $\begin{array}{l}\text { Expertos ISO de paí- } \\
\text { ses miembros; em- } \\
\text { presas represen- } \\
\text { tantes, organizacio- } \\
\text { nes de estandari- } \\
\text { zación, consultores, } \\
\text { gobiernos, organi- } \\
\text { zaciones no guber- } \\
\text { namentales. }\end{array}$ & 1987 & $\begin{array}{l}\text { Certificación sobre } \\
\text { el cumplimiento de } \\
\text { sistemas de ges- } \\
\text { tión en los proce- } \\
\text { sos productivos y } \\
\text { en la ejecución del } \\
\text { servicio. }\end{array}$ \\
\hline $\begin{array}{l}\text { SERIE } \\
\text { ISO } 14000\end{array}$ & $\begin{array}{l}\text { Desarrollar estándares } \\
\text { internacionales que sir- } \\
\text { van de guía en la ges- } \\
\text { tión y comunicación de } \\
\text { sistemas medioambien- } \\
\text { tales, ofreciendo princi- } \\
\text { pios y lineamientos so- } \\
\text { bre cómo prevenir el } \\
\text { daño ambiental. }\end{array}$ & $\begin{array}{l}\text { Organización inter- } \\
\text { nacional para la } \\
\text { estandarización } \\
\text { (ISO, por sus siglas } \\
\text { en inglés) }\end{array}$ & $\begin{array}{l}\text { Provee criterios para } \\
\text { priorizar, integrar, } \\
\text { comunicar y monito- } \\
\text { rear el desempeño } \\
\text { medioambiental. }\end{array}$ & $\begin{array}{l}\text { Expertos ISO de paí- } \\
\text { ses miembros; em- } \\
\text { presas represen- } \\
\text { tantes, organizacio- } \\
\text { nes de estandari- } \\
\text { zación, consultores, } \\
\text { gobiernos, organi- } \\
\text { zaciones no guber- } \\
\text { namentales. }\end{array}$ & 1993 & $\begin{array}{l}\text { Certificación sobre } \\
\text { sistemas de ges- } \\
\text { tión ambiental. }\end{array}$ \\
\hline SA 8000 & $\begin{array}{l}\text { Mejorar las condiciones } \\
\text { laborales en el mundo, } \\
\text { mediante la propuesta } \\
\text { de un estándar sobre } \\
\text { trabajo humano y siste- } \\
\text { mas de verificación, y la } \\
\text { divulgación de informa- } \\
\text { ción al público. }\end{array}$ & $\begin{array}{l}\text { Accountability } \\
\text { International (SAI), } \\
\text { directorio asesor } \\
\text { con representa- } \\
\text { ción de grupos de } \\
\text { interés, que incluye } \\
\text { expertos del sector } \\
\text { empresarial, go- } \\
\text { bierno, asociacio- } \\
\text { nes de intercambio } \\
\text { y organizaciones } \\
\text { no gubernamenta- } \\
\text { les. }\end{array}$ & $\begin{array}{l}\text { Derechos laborales; } \\
\text { certificación de faci- } \\
\text { lidades para el cen- } \\
\text { tro de trabajo de } \\
\text { acuerdo con están- } \\
\text { dares; intercambio y } \\
\text { guía. }\end{array}$ & $\begin{array}{l}\text { Empresas y sus pro- } \\
\text { veedores, asocia- } \\
\text { ciones comerciales, } \\
\text { sindicatos y trabaja- } \\
\text { dores, empresas au- } \\
\text { ditoras, organiza- } \\
\text { ciones no guberna- } \\
\text { mentales, gobierno, } \\
\text { organizaciones mul- } \\
\text { tilaterales. }\end{array}$ & 1997 & $\begin{array}{l}\text { SA8000 es un } \\
\text { estándar y sistema } \\
\text { de verificación del } \\
\text { lugar de trabajo. }\end{array}$ \\
\hline OHSAS 1800 & $\begin{array}{l}\text { Contribuir en el estable- } \\
\text { cimiento de un sistema } \\
\text { de gestión de la salud y } \\
\text { seguridad ocupacional } \\
\text { para reducir riesgos } \\
\text { asociados a la actividad } \\
\text { de la organización. Per- } \\
\text { mite definir políticas y un } \\
\text { sistema de prevención } \\
\text { que puede ser certi- } \\
\text { ficable por una organi- } \\
\text { zación externa.Emitir } \\
\text { una norma concertada } \\
\text { de alcance internacio- } \\
\text { nal. }\end{array}$ & $\begin{array}{l}\text { Grupo de organiza- } \\
\text { ciones en el tema } \\
\text { de salud y seguri- } \\
\text { dad ocupacional } \\
\text { que intentan con- } \\
\text { certar una norma } \\
\text { internacional, lide- } \\
\text { rados por la British } \\
\text { Standars Institution. }\end{array}$ & $\begin{array}{l}\text { Provee normativa } \\
\text { para la planificación } \\
\text { y puesta en marcha } \\
\text { de un sistema de } \\
\text { gestión de la salud y } \\
\text { seguridad ocupa- } \\
\text { cional. }\end{array}$ & $\begin{array}{l}\text { Esfuerzo concerta- } \\
\text { do de los grupos } \\
\text { promotores de la } \\
\text { norma. }\end{array}$ & 1999 & $\begin{array}{l}\text { Certificación en } \\
\text { cuanto al proceso } \\
\text { de creación de un } \\
\text { sistema de gestión } \\
\text { de salud y seguri- } \\
\text { dad ocupacional. }\end{array}$ \\
\hline
\end{tabular}

Elaboración propia, a partir de CEPYME-Aragón (2003), Normas ISO (<http://www.iso-14001.org.uk> y <http://www.iso.ch>) y SAI (2001). 
Anexo 3

Índices para la inversión responsable

\begin{tabular}{|c|c|c|c|c|c|c|}
\hline & $\begin{array}{l}\text { Objetivo } \\
\text { central }\end{array}$ & $\begin{array}{l}\text { Institución } \\
\text { creadora del } \\
\text { instrumento }\end{array}$ & $\begin{array}{l}\text { Ambito de } \\
\text { acción }\end{array}$ & $\begin{array}{l}\text { Participantes } \\
\text { en la formación } \\
\text { del instrumento }\end{array}$ & Inicio & Uso \\
\hline $\begin{array}{l}\text { Dow Jones } \\
\text { Sustainability } \\
\text { Index }\end{array}$ & $\begin{array}{l}\text { Proveer de medidas de } \\
\text { comparación o benchmarh } \\
\text { confiables y objetivas } \\
\text { para el análisis de la } \\
\text { sostenibilidad de los } \\
\text { portafolios de inversión } \\
\text { Promover la inversión } \\
\text { responsable; es decir, } \\
\text { localizada en empresas } \\
\text { que muestran prácticas } \\
\text { alineadas a los princi- } \\
\text { pios del desarrollo sos- } \\
\text { tenible y la responsabi- } \\
\text { lidad social. }\end{array}$ & $\begin{array}{l}\text { Dow Jones indexes, } \\
\text { STOXXLimitedy SAM. }\end{array}$ & Mundial & $\begin{array}{l}\text { Expertos del Dow } \\
\text { Jones Global Index. }\end{array}$ & 1999 & $\begin{array}{l}\text { Medida de evalua- } \\
\text { ción de comporta- } \\
\text { miento responsable } \\
\text { y orientado a la } \\
\text { sostenibilidad para } \\
\text { realizar inversiones } \\
\text { con este filtro de } \\
\text { selección. }\end{array}$ \\
\hline $\begin{array}{l}\text { DOMINI } 400 \\
\text { Index }\end{array}$ & $\begin{array}{l}\text { Analiza el desempeño } \\
\text { de las empresas que co- } \\
\text { tizan en el mercado bur- } \\
\text { sátil americano, y otras } \\
\text { seleccionadas expre- } \\
\text { samente, con la finali- } \\
\text { dad de evaluar su com- } \\
\text { portamiento social } \\
\text { monitorizar si estas prác- } \\
\text { ticas generan o no sobre- } \\
\text { costos financieros. }\end{array}$ & $\begin{array}{l}\text { KLD Research \& } \\
\text { Analytics, Inc. }\end{array}$ & $\begin{array}{l}\text { Estados Unidos } \\
\text { de Norteamérica. }\end{array}$ & $\begin{array}{l}\text { Empresas del Stan- } \\
\text { dard \& Poors } 500 \\
\text { Index, más empre- } \\
\text { sas reconocidas en } \\
\text { los Estados Unidos } \\
\text { y empresas cono- } \\
\text { cidas por sus bue- } \\
\text { nas prácticas so- } \\
\text { ciales. }\end{array}$ & $\begin{array}{l}1993 \\
1997\end{array}$ & $\begin{array}{l}\text { Monitorización del } \\
\text { desempeño finan- } \\
\text { ciero de empresas } \\
\text { con buenas prácti- } \\
\text { cas sociales y refe- } \\
\text { rencia para inver- } \\
\text { sores responsa- } \\
\text { bles. }\end{array}$ \\
\hline $\begin{array}{l}\text { FTSE4 } \\
\text { Good } \\
\text { Index }\end{array}$ & $\begin{array}{l}\text { Proveer a inversionistas } \\
\text { y gestores de activos fi- } \\
\text { nancieros información } \\
\text { sobre empresas con } \\
\text { prácticas responsables, } \\
\text { que cumplen con los } \\
\text { estándares internacio- } \\
\text { nales sobre el tema. Pro- } \\
\text { mover las prácticas res- } \\
\text { ponsables en el mundo } \\
\text { Se busca que sea el ín- } \\
\text { dice de referencia glo- } \\
\text { bal en el marco de las in- } \\
\text { versiones socialmente } \\
\text { responsables. }\end{array}$ & $\begin{array}{l}\text { FTSE, compañía in- } \\
\text { dependiente en la } \\
\text { rama de creación de } \\
\text { índices y servicios de } \\
\text { información. Impul- } \\
\text { sado por Ethical } \\
\text { Investment Research } \\
\text { Services (EIRIS) y } \\
\text { UNICEF. }\end{array}$ & $\begin{array}{l}\text { Europa, Reino } \\
\text { Unido, Estados } \\
\text { Unidos y un } \\
\text { último grupo en } \\
\text { el nivel global. }\end{array}$ & n. d. & 1999 & $\begin{array}{l}\text { Medida de evalua- } \\
\text { ción de comporta- } \\
\text { miento responsable } \\
\text { y orientado a la } \\
\text { sostenibilidad para } \\
\text { realizar inversiones } \\
\text { con este filtro de } \\
\text { selección. }\end{array}$ \\
\hline $\begin{array}{l}\text { Ethibel } \\
\text { Sustainability } \\
\text { Index (ESI) }\end{array}$ & $\begin{array}{l}\text { Provee de una perspec- } \\
\text { tiva amplia del desempe- } \\
\text { ño financiero de las em- } \\
\text { presas líderes mundia- } \\
\text { les, en términos de su } \\
\text { enfoque sostenible. }\end{array}$ & $\begin{array}{l}\text { Ethibel agrupa cua- } \\
\text { tro índices regiona- } \\
\text { les: ESI Global, ESI } \\
\text { Americas, ESI Europe } \\
\text { y ESI Asia Pacific. } \\
\text { Contrata los servi- } \\
\text { cios de Standard \& } \\
\text { Poors para calcular y } \\
\text { mantener el índice. }\end{array}$ & $\begin{array}{l}\text { Mundial, de } \\
\text { origen belga. }\end{array}$ & Standard \& Poors & & $\begin{array}{l}\text { Información orien- } \\
\text { tada a inversores, } \\
\text { gestores de activos } \\
\text { financieros, bancos } \\
\text { e inversores del } \\
\text { campo del comercio } \\
\text { para la realización } \\
\text { de sus inversiones } \\
\text { responsables. }\end{array}$ \\
\hline
\end{tabular}

n. d.: información no disponible.

Elaboración propia, a partir de Domini Social Investments (<http://www.domini.com>), DJSI y World Index Design Committee (2004, <http://www.sustainability-indexes.com>), FTSE (2003, <http://www.ftse.com>) y Ethibel (<http://www.ethibel.org>). 
Un instrumento de medida para conocer las tendencias de los directivos en la priorización de las acciones de Responsabilidad Social Empresarial (RSE)

Anexo 4

Estándares y sistemas orientados a la divulgación de información y a la rendición de cuentas

\begin{tabular}{|c|c|c|c|c|c|c|}
\hline & $\begin{array}{l}\text { Objetivo } \\
\text { central }\end{array}$ & $\begin{array}{l}\text { Institución } \\
\text { creadora del } \\
\text { instrumento }\end{array}$ & $\begin{array}{l}\text { Ambito de } \\
\text { acción }\end{array}$ & $\begin{array}{l}\text { Participantes } \\
\text { en la formación } \\
\text { del instrumento }\end{array}$ & Inicio & Uso \\
\hline GRI & $\begin{array}{l}\text { Sistema que busca con- } \\
\text { vertir la divulgación de } \\
\text { información económi- } \\
\text { ca, ambiental y social en } \\
\text { una práctica habitual } \\
\text { con elevados están- } \\
\text { dares de rigurosidad y } \\
\text { comparación, median- } \\
\text { te el desarrollo de un } \\
\text { marco aceptado en el } \\
\text { nivel general. }\end{array}$ & $\begin{array}{l}\text { GRI, cuyo directorio } \\
\text { está compuesto por } \\
\text { representantes de } \\
\text { múltiples agentes } \\
\text { sociales. }\end{array}$ & $\begin{array}{l}\text { Desempeño econó- } \\
\text { mico, ambiental y so- } \\
\text { cial; divulgación de } \\
\text { información al pú- } \\
\text { blico. }\end{array}$ & $\begin{array}{l}\text { Compañías, Nacio- } \\
\text { nes Unidas, grupos } \\
\text { ambientalistas, la- } \\
\text { borales y de defen- } \\
\text { sa de los derechos } \\
\text { humanos; asocia- } \\
\text { ciones industriales } \\
\text { y de rendición de } \\
\text { cuentas; gobier- } \\
\text { nos. }\end{array}$ & 1997 & $\begin{array}{l}\text { GRI es un marco } \\
\text { para informar sobre } \\
\text { principios, caracte- } \\
\text { rísticas e indicado- } \\
\text { res de desarrollo } \\
\text { sostenible. }\end{array}$ \\
\hline AA1000 & $\begin{array}{l}\text { Estándar que busca } \\
\text { mejorar la rendición de } \\
\text { cuentas y el desempe- } \\
\text { ño general de la orga- } \\
\text { nización, a partir de la } \\
\text { promoción específica } \\
\text { de la rendición de cuen- } \\
\text { tas y auditoría de aspec- } \\
\text { tos éticos y sociales. }\end{array}$ & $\begin{array}{l}\text { International Council } \\
\text { of the Institute of } \\
\text { Social and Ethical } \\
\text { Accountability y otros } \\
\text { agentes sociales. }\end{array}$ & $\begin{array}{l}\text { Contabilidad, audito- } \\
\text { ría, informe social y } \\
\text { ética; diálogo con } \\
\text { agentes sociales y } \\
\text { aseguramiento de la } \\
\text { calidad. }\end{array}$ & $\begin{array}{l}\text { Miembros de varios } \\
\text { tipos de agentes } \\
\text { sociales.AA1000 } \\
\text { es propuesto por } \\
\text { empresas y organi-- } \\
\text { zaciones no guber- } \\
\text { namentales. }\end{array}$ & 1999 & $\begin{array}{l}\text { AA1000 está basada } \\
\text { en principios de } \\
\text { accountability y en } \\
\text { procesos de rendi- } \\
\text { ción de cuentas a los } \\
\text { agentes sociales. } \\
\text { AA1000 ofrece un } \\
\text { mecanismo riguro- } \\
\text { so, basado en la ge- } \\
\text { neración de indi- } \\
\text { cadores de susten- } \\
\text { tabilidad, orientado } \\
\text { a generar un víncu- } \\
\text { lo con los agentes } \\
\text { sociales. } \\
\end{array}$ \\
\hline $\begin{array}{l}\text { MANUAL } \\
\text { DE } \\
\text { BALANCE } \\
\text { SOCIAL } \\
\text { OIT/CONFIEP }\end{array}$ & $\begin{array}{l}\text { Informe que permite } \\
\text { reunir información } \\
\text { cuantitativa y cualitati- } \\
\text { va por medio de la cual } \\
\text { se puede seguir, de } \\
\text { manera objetiva, el } \\
\text { desarrollo de las acti- } \\
\text { vidades de la empresa } \\
\text { en el tema social y la- } \\
\text { boral. Es decir, en el } \\
\text { campo interno (recur- } \\
\text { sos humanos) y exter- } \\
\text { no (relaciones con pú- } \\
\text { blicos primarios, con la } \\
\text { comunidad y con otras } \\
\text { instituciones). }\end{array}$ & $\begin{array}{l}\text { Organización Inter- } \\
\text { nacional del Trabajo } \\
\text { (OIT) y la Confede- } \\
\text { ración Nacional de } \\
\text { Instituciones Empre- } \\
\text { sariales Privadas del } \\
\text { Perú (Confiep) }\end{array}$ & $\begin{array}{l}\text { Manual para la elabo- } \\
\text { ración del balance } \\
\text { social voluntario en el } \\
\text { Perú. Incluye desem- } \\
\text { peño laboral y social. }\end{array}$ & $\begin{array}{l}\text { Elaborado por la } \\
\text { OIT y la Confiep. }\end{array}$ & 1997 & $\begin{array}{l}\text { Manual de referen- } \\
\text { cia para empresas } \\
\text { que desean prepa- } \\
\text { rar el Balance so- } \\
\text { cial. }\end{array}$ \\
\hline $\begin{array}{l}\text { MANUAL DE } \\
\text { BALANCE } \\
\text { SOCIAL DE } \\
\text { DERES }\end{array}$ & $\begin{array}{l}\text { Hacer pública la RSC, } \\
\text { construyendo mayores } \\
\text { vínculos entre la empre- } \\
\text { sa, su personal y pro- } \\
\text { pietarios, la sociedad y } \\
\text { el medioambiente. }\end{array}$ & $\begin{array}{l}\text { Deres, organización } \\
\text { integrada por em- } \\
\text { presas, organizacio- } \\
\text { nes empresariales e } \\
\text { instituciones de Uru- } \\
\text { guay. }\end{array}$ & $\begin{array}{l}\text { Manual para la elabo- } \\
\text { ración del balance } \\
\text { social voluntario en } \\
\text { Uruguay. Incluye ge- } \\
\text { neración de valor y } \\
\text { desempeño económi- } \\
\text { co, social y ambiental. }\end{array}$ & $\begin{array}{l}\text { Grupo importante } \\
\text { de dirigentes em- } \\
\text { presariales uru- } \\
\text { guayos con la Uni- } \\
\text { versidad Católica } \\
\text { del Uruguay y } \\
\text { miembros de Deres. }\end{array}$ & 1999 & $\begin{array}{l}\text { Manual de referen- } \\
\text { cia para empresas } \\
\text { que desean prepa- } \\
\text { rar el Balance so- } \\
\text { cial. }\end{array}$ \\
\hline
\end{tabular}

Elaboración propia, a partir de Confiep y OIT (1997), Deres (1999), GRI (2006, 2002), The Institute of Social and Ethical Accountability (1999) y <http://www.accountability.org.uk>. 
Anexo 5

Validación de cada factor

\begin{tabular}{|c|c|c|c|c|c|}
\hline \multicolumn{6}{|c|}{ FACTOR 1: PRIORIDAD EN EL ÁMBITO MEDIOAMBIENTAL } \\
\hline Variable & $\begin{array}{l}\text { Puntuación } \\
\text { media }\end{array}$ & $\begin{array}{c}\text { Carga } \\
\text { factorial }\end{array}$ & $\begin{array}{c}\text { MSA } \\
\text { individual }\end{array}$ & $\begin{array}{l}\text { Correlac. } \\
\text { ítem-total }\end{array}$ & $\begin{array}{l}\text { Alpha de } \\
\text { Cronbach } \\
\text { por factor }\end{array}$ \\
\hline $\begin{array}{l}\text { Incorporación en la planificación estratégica de objetivos } \\
\text { vinculados con la gestión medioambiental. }\end{array}$ & 3,64 & 0,87 & 0,86 & 0,89 & 0,956 \\
\hline $\begin{array}{l}\text { Rendición de cuentas ante públicos internos y externos } \\
\text { a la empresa sobre la gestión medioambiental. }\end{array}$ & 3,55 & 0,86 & 0,82 & 0,87 & \\
\hline $\begin{array}{l}\text { Capacitación de las diversas instancias de la empresa } \\
\text { (propietarios, directivos y trabajadores) en buenas prác- } \\
\text { ticas medioambientales. }\end{array}$ & 3,75 & 0,84 & 0,82 & 0,87 & \\
\hline $\begin{array}{l}\text { Desarrollo de sistemas de evaluación y monitoreo de la } \\
\text { gestión medioambiental. }\end{array}$ & 3,77 & 0,84 & 0,76 & 0,87 & \\
\hline $\begin{array}{l}\text { Adopción de estándares o sistemas internacionales de } \\
\text { calidad en la gestión medioambiental. }\end{array}$ & 3,78 & 0,82 & 0,75 & 0,44 & \\
\hline $\begin{array}{l}\text { Evaluación del impacto ambiental de la actividad de la } \\
\text { empresa en el entorno. }\end{array}$ & 4,02 & 0,82 & 0,74 & 0,81 & \\
\hline $\begin{array}{l}\text { Asignación de recursos financieros, tecnológicos, mate- } \\
\text { riales y humanos y definición de instancias formales } \\
\text { responsables de la gestión medioambiental. }\end{array}$ & 3,72 & 0,81 & 0,77 & 0,85 & \\
\hline $\begin{array}{l}\text { Realización de campañas y acciones de promoción y } \\
\text { defensa de los temas de cuidado ambiental en la comu- } \\
\text { nidad. }\end{array}$ & 3,33 & 0,67 & 0,86 & 0,78 & \\
\hline $\begin{array}{l}\text { Desarrollo de programas internos de ahorro de energía, } \\
\text { uso eficiente de agua y materiales, control de residuos } \\
\text { sólidos, proyectos de reciclaje, etcétera. }\end{array}$ & 4.08 & 0,66 & 0,79 & 0,65 & \\
\hline $\begin{array}{l}\text { Apoyo a programas o iniciativas con terceros orientadas } \\
\text { a la conservación de los recursos naturales y/o al desa- } \\
\text { rrollo de sistemas de gestión medioambiental. }\end{array}$ & 3,23 & 0,64 & 0,74 & 0,71 & \\
\hline $\begin{array}{l}\text { Apoyo en el desarrollo de competencias en la gestión } \\
\text { medioambiental de proveedores, intermediarios, agen- } \\
\text { tes, socios estratégicos y clientes. }\end{array}$ & 3,09 & 0,60 & 0,73 & 0,72 & \\
\hline $\begin{array}{l}\text { Consideración de criterios ambientales para favorecer } \\
\text { las condiciones otorgadas a proveedores, intermedia- } \\
\text { rios, agentes y socios estratégicos. }\end{array}$ & 2,82 & 0,59 & 0,72 & 0,72 & \\
\hline $\begin{array}{l}\text { Consideración de criterios ambientales para favorecer } \\
\text { las condiciones otorgadas a clientes. }\end{array}$ & 3,22 & 0,51 & 0,61 & 0,57 & \\
\hline $\begin{array}{l}\text { Adopción de estándares o sistemas internacionales de } \\
\text { calidad en la gestión de la oferta de productos y de la } \\
\text { atención y servicio al cliente. }\end{array}$ & 4,61 & 0,49 & 0,73 & 0,85 & \\
\hline $\begin{array}{l}\text { Implementación de canales permanentes de diálogo con } \\
\text { grupos de interés. }\end{array}$ & 4,13 & 0,47 & 0,69 & 0,52 & \\
\hline
\end{tabular}


(Continuación)

\begin{tabular}{|c|c|c|c|c|c|}
\hline \multicolumn{6}{|c|}{ FACTOR 2: PRIORIDAD EN EL ÁMBITO LABORAL } \\
\hline Variable & $\begin{array}{l}\text { Puntuación } \\
\text { media }\end{array}$ & $\begin{array}{c}\text { Carga } \\
\text { factorial }\end{array}$ & $\begin{array}{c}\text { MSA } \\
\text { individual }\end{array}$ & \begin{tabular}{l|} 
Correlac. \\
ítem-total
\end{tabular} & $\begin{array}{l}\text { Alpha de } \\
\text { Cronbach } \\
\text { por factor }\end{array}$ \\
\hline $\begin{array}{l}\text { Desarrollo de programas de salud, seguridad y bienestar } \\
\text { para el trabajador. }\end{array}$ & 4,55 & 0,76 & 0,78 & 0,65 & 0,917 \\
\hline $\begin{array}{l}\text { Incorporación en la planificación estratégica de objetivos } \\
\text { vinculados con la gestión laboral. }\end{array}$ & 4,24 & 0,69 & 0,72 & 0,70 & \\
\hline $\begin{array}{l}\text { Aplicación de modalidades de contratación del personal, } \\
\text { bajo criterios de justicia, no discriminación y equidad para } \\
\text { el trabajador. }\end{array}$ & 4,63 & 0,68 & 0,57 & 0,56 & \\
\hline $\begin{array}{l}\text { Asignación de recursos financieros, tecnológicos, mate- } \\
\text { riales y humanos y definición de instancias formales res- } \\
\text { ponsables de la gestión laboral. }\end{array}$ & 4,15 & 0,65 & 0,85 & 0,72 & \\
\hline $\begin{array}{l}\text { Implementación de programas de capacitación y desarro- } \\
\text { llo laboral y personal del trabajador. }\end{array}$ & 4,30 & 0,63 & 0,69 & 0,70 & \\
\hline $\begin{array}{l}\text { Capacitación de las diversas instancias de la empresa } \\
\text { (propietarios, directivos y trabajadores) en buenas prácti- } \\
\text { cas laborales. }\end{array}$ & 4,13 & 0,62 & 0,81 & 0,71 & \\
\hline Implementación de programas de retención del personal. & 3,91 & 0,61 & 0,70 & 0,66 & \\
\hline $\begin{array}{l}\text { Desarrollo de programas para la mejora de la calidad de } \\
\text { vida del trabajador y su familia. }\end{array}$ & 4,00 & 0,61 & 0,72 & 0,55 & \\
\hline $\begin{array}{l}\text { Rendición de cuentas ante públicos internos y externos a } \\
\text { la empresa sobre la gestión laboral. }\end{array}$ & 4,42 & 0,59 & 0,76 & 0,62 & \\
\hline $\begin{array}{l}\text { Adopción de estándares o sistemas internacionales de } \\
\text { calidad en la gestión laboral. }\end{array}$ & 3,77 & 0,59 & 0,79 & 0,73 & \\
\hline $\begin{array}{l}\text { Generación de mecanismos de consulta a los trabajado- } \\
\text { res sobre su satisfacción con la empresa y sus procesos } \\
\text { de gestión. }\end{array}$ & 4,10 & 0,57 & 0,84 & 0,74 & \\
\hline Cumplimiento de obligaciones con el Estado. & 4,85 & 0,57 & 0,72 & 0,58 & \\
\hline $\begin{array}{l}\text { Desarrollo de sistemas de información para la promoción, } \\
\text { al interior de la empresa, de los derechos de los trabaja- } \\
\text { dores. }\end{array}$ & 3,97 & 0,52 & 0,62 & 0,45 & \\
\hline $\begin{array}{l}\text { Rendición de cuentas ante públicos internos y externos a } \\
\text { la empresa sobre la oferta de productos y la atención y } \\
\text { servicio al cliente. }\end{array}$ & 3,88 & 0,48 & 0,64 & 0,54 & \\
\hline $\begin{array}{l}\text { Desarrollo de sistemas de evaluación y monitoreo de la } \\
\text { gestión laboral. }\end{array}$ & 4,21 & 0,40 & 0,64 & 0,60 & \\
\hline
\end{tabular}


(Continuación)

\begin{tabular}{|c|c|c|c|c|c|}
\hline \multicolumn{6}{|c|}{ FACTOR 3: PRIORIDAD EN EL ÁMBITO SOCIAL } \\
\hline Variable & $\begin{array}{l}\text { Puntuación } \\
\text { media }\end{array}$ & $\begin{array}{c}\text { Carga } \\
\text { factorial }\end{array}$ & $\begin{array}{c}\text { MSA } \\
\text { individual }\end{array}$ & $\begin{array}{l}\text { Correlac. } \\
\text { ítem-total }\end{array}$ & $\begin{array}{l}\text { Alpha de } \\
\text { Cronbach } \\
\text { por factor }\end{array}$ \\
\hline $\begin{array}{l}\text { Asignación de recursos financieros, tecnológicos, mate- } \\
\text { riales y humanos y definición de instancias formales } \\
\text { responsables de la gestión de programas sociales. }\end{array}$ & 3,80 & 0,70 & 0,85 & 0,85 & 0,939 \\
\hline $\begin{array}{l}\text { Desarrollo de proyectos de inversión social con benefi- } \\
\text { cios esperados para la comunidad y para la empresa } \\
\text { (en temas como: desarrollo de capacidades de mano de } \\
\text { obra, creación de empresas, entre otros). }\end{array}$ & 3,90 & 0,70 & 0,74 & 0,76 & \\
\hline $\begin{array}{l}\text { Adopción de estándares o sistemas internacionales de } \\
\text { calidad en la gestión de programas sociales. }\end{array}$ & 3,13 & 0,64 & 0,80 & 0,79 & \\
\hline $\begin{array}{l}\text { Desarrollo de sistemas de evaluación y monitoreo de la } \\
\text { gestión de programas sociales. }\end{array}$ & 3,36 & 0,64 & 0,73 & 0,80 & \\
\hline $\begin{array}{l}\text { Monitoreo del impacto que la presencia de la empresa } \\
\text { genera en la comunidad. }\end{array}$ & 3,58 & 0,63 & 0,88 & 0,79 & \\
\hline $\begin{array}{l}\text { Capacitación de las diversas instancias de la empresa } \\
\text { (propietarios, directivos y trabajadores) en la gestión de } \\
\text { programas sociales. }\end{array}$ & 3,39 & 0,62 & 0,89 & 0,81 & \\
\hline $\begin{array}{l}\text { Promoción de la participación de los clientes, proveedo- } \\
\text { res, intermediarios, agentes y socios estratégicos en } \\
\text { programas sociales. }\end{array}$ & 3,32 & 0,62 & 0,72 & 0,72 & \\
\hline $\begin{array}{l}\text { Incorporación en la planificación estratégica de objetivos } \\
\text { vinculados con la gestión de programas sociales. }\end{array}$ & 3,87 & 0,61 & 0,80 & 0,82 & \\
\hline $\begin{array}{l}\text { Rendición de cuentas ante públicos internos y externos } \\
\text { a la empresa sobre la gestión de programas sociales. }\end{array}$ & 3,54 & 0,57 & 0,85 & 0,77 & \\
\hline $\begin{array}{l}\text { Colaboración con el Gobierno, con organizaciones del } \\
\text { sector civil u otros agentes del entorno para la realiza- } \\
\text { ción de acciones conjuntas en favor del desarrollo de la } \\
\text { comunidad. }\end{array}$ & 3,58 & 0,56 & 0,72 & 0,60 & \\
\hline $\begin{array}{l}\text { Cumplimiento estricto de compromisos con proveedo- } \\
\text { res, intermediarios, agentes y socios estratégicos según } \\
\text { condiciones contractuales. }\end{array}$ & 4,58 & 0,45 & 0,77 & 0,45 & \\
\hline $\begin{array}{l}\text { Participación en órganos de la sociedad civil orientados } \\
\text { a la defensa de los derechos de la ciudadanía. }\end{array}$ & 3,09 & 0,40 & 0,62 & 0,52 & \\
\hline
\end{tabular}


Un instrumento de medida para conocer las tendencias de los directivos en la priorización de las acciones de Responsabilidad Social Empresarial (RSE)

\begin{tabular}{|c|c|c|c|c|c|}
\hline \multicolumn{6}{|c|}{ FACTOR 4: PRIORIDAD EN EL ÁMBITO DE LA GESTIÓN DE LA CADENA DE SUMINISTRO } \\
\hline Variable & $\begin{array}{l}\text { Puntuación } \\
\text { media }\end{array}$ & $\begin{array}{c}\text { Carga } \\
\text { factorial }\end{array}$ & $\begin{array}{l}\text { MSA } \\
\text { individual }\end{array}$ & $\begin{array}{l}\text { Correlac. } \\
\text { ítem-total }\end{array}$ & $\begin{array}{l}\text { Alpha de } \\
\text { Cronbach } \\
\text { por factor }\end{array}$ \\
\hline $\begin{array}{l}\text { Asignación de recursos financieros, tecnológicos, } \\
\text { materiales y humanos y definición de instancias formales } \\
\text { responsables de la gestión de las relaciones con } \\
\text { proveedores, intermediarios, agentes y socios } \\
\text { estratégicos. }\end{array}$ & 3,95 & 0,79 & 0,73 & 0,76 & 0,922 \\
\hline $\begin{array}{l}\text { Incorporación en la planificación estratégica de objetivos } \\
\text { vinculados con la gestión de las relaciones con } \\
\text { proveedores, intermediarios, agentes y socios } \\
\text { estratégicos. }\end{array}$ & 4,12 & 0,76 & 0,67 & 0,73 & \\
\hline $\begin{array}{l}\text { Desarrollo de sistemas de evaluación y monitoreo de la } \\
\text { gestión de las relaciones con los proveedores, } \\
\text { intermediarios, agentes y socios estratégicos. }\end{array}$ & 3,90 & 0,72 & 0,76 & 0,77 & \\
\hline $\begin{array}{l}\text { Adopción de estándares o sistemas internacionales de } \\
\text { calidad en la gestión de las relaciones con los } \\
\text { proveedores, intermediarios, agentes y socios } \\
\text { estratégicos. }\end{array}$ & 4,00 & 0,71 & 0,86 & 0,77 & \\
\hline $\begin{array}{l}\text { Rendición de cuentas ante públicos internos y externos } \\
\text { a la empresa sobre la gestión de las relaciones con los } \\
\text { proveedores, intermediarios, agentes y socios } \\
\text { estratégicos. }\end{array}$ & 3,66 & 0,71 & 0,74 & 0,78 & \\
\hline $\begin{array}{l}\text { Capacitación y participación de las diversas instancias } \\
\text { de la empresa (propietarios, directivos y trabajadores) } \\
\text { en la gestión de las relaciones con los proveedores, } \\
\text { intermediarios, agentes y socios estratégicos. }\end{array}$ & 3,97 & 0,68 & 0,86 & 0,79 & \\
\hline $\begin{array}{l}\text { Desarrollo de iniciativas para la mejora de las } \\
\text { competencias de proveedores, intermediarios, agentes } \\
\text { y socios estratégicos. }\end{array}$ & 3,85 & 0,64 & 0,74 & 0,62 & \\
\hline $\begin{array}{l}\text { Desarrollo de políticas comerciales que aseguren } \\
\text { condiciones justas en el trato a proveedores, } \\
\text { intermediarios, agentes y socios estratégicos. }\end{array}$ & 4,29 & 0,63 & 0,74 & 0,65 & \\
\hline $\begin{array}{l}\text { Apoyo a proveedores, intermediarios, agentes y socios } \\
\text { estratégicos en la implementación de una gestión } \\
\text { socialmente responsible. }\end{array}$ & 3,63 & 0,62 & 0,76 & 0,67 & \\
\hline $\begin{array}{l}\text { Generación de mecanismos de consulta a los } \\
\text { proveedores, intermediarios, agentes y socios } \\
\text { estratégicos sobre su satisfacción con la empresa. }\end{array}$ & 3,58 & 0,62 & 0,78 & 0,68 & \\
\hline $\begin{array}{l}\text { Desarrollo de políticas explícitas de información } \\
\text { transparente sobre condiciones contractuales a } \\
\text { proveedores, intermediarios, agentes y socios } \\
\text { estratégicos. }\end{array}$ & 4,45 & 0,50 & 0,76 & 0,50 & \\
\hline $\begin{array}{l}\text { Selección de proveedores, intermediarios, agentes y } \\
\text { socios estratégicos con criterios de apoyo social. }\end{array}$ & 3,38 & 0,45 & 0,52 & 0,45 & \\
\hline
\end{tabular}


(Continuación)

\begin{tabular}{|c|c|c|c|c|c|}
\hline \multicolumn{6}{|c|}{ FACTOR 5: PRIORIDAD EN EL ÁMBITO DE LA TRANSPARENCIA, LOS VALORES Y EL GOBIERNO CORPORATIVO } \\
\hline Variable & $\begin{array}{l}\text { Puntuación } \\
\text { media }\end{array}$ & $\begin{array}{c}\text { Carga } \\
\text { factorial }\end{array}$ & $\begin{array}{c}\text { MSA } \\
\text { individual }\end{array}$ & $\begin{array}{l}\text { Correlac. } \\
\text { ítem-total }\end{array}$ & $\begin{array}{l}\text { Alpha de } \\
\text { Cronbach } \\
\text { por factor }\end{array}$ \\
\hline $\begin{array}{l}\text { Adopción de estándares o sistemas internacionales de } \\
\text { calidad en la gestión de la transparencia, los valores y } \\
\text { el buen gobierno corporativo. }\end{array}$ & 4,21 & 0,80 & 0,77 & 0,81 & 0,913 \\
\hline $\begin{array}{l}\text { Desarrollo de sistemas de evaluación y monitoreo de la } \\
\text { gestión de la transparencia, los valores y el buen gobierno } \\
\text { corporativo. }\end{array}$ & 4,10 & 0,76 & 0,76 & 0,81 & \\
\hline $\begin{array}{l}\text { Asignación de recursos financieros, tecnológicos, } \\
\text { materiales y humanos y definición de instancias formales } \\
\text { responsables de la definición, comunicación, defensa y } \\
\text { evaluación de los temas de transparencia, valores y } \\
\text { buen gobierno corporativo. }\end{array}$ & 4,22 & 0,70 & 0,75 & 0,76 & \\
\hline $\begin{array}{l}\text { Utilización de códigos de ética que establezcan posición } \\
\text { de la empresa sobre corrupción, soborno, derechos } \\
\text { humanos, discriminación y otros dilemas éticos. }\end{array}$ & 4,56 & 0,69 & 0,77 & 0,72 & \\
\hline $\begin{array}{l}\text { Incorporación en la planificación estratégica de objetivos } \\
\text { vinculados con los temas de transparencia, valores y } \\
\text { buen gobierno corporativo. }\end{array}$ & 4,51 & 0,65 & 0,81 & 0,74 & \\
\hline $\begin{array}{l}\text { Rendición de cuentas ante públicos internos y externos } \\
\text { a la empresa sobre la gestión de la transparencia, los } \\
\text { valores y el buen gobierno corporativo. }\end{array}$ & 4,06 & 0,65 & 0,76 & 0,72 & \\
\hline $\begin{array}{l}\text { Capacitación de las diversas instancias de la empresa } \\
\text { (propietarios, directivos y trabajadores) en buenas } \\
\text { prácticas de gobierno corporativo. }\end{array}$ & 4,02 & 0,64 & 0,63 & 0,69 & \\
\hline $\begin{array}{l}\text { Desarrollo de mecanismos de evaluación del desempeño } \\
\text { del directorio y de la alta dirección de la empresa. }\end{array}$ & 3,59 & 0,59 & 0,64 & 0,59 & \\
\hline $\begin{array}{l}\text { Implementación de políticas de evaluación e incentivos } \\
\text { al personal, que contemplen objetivos vinculados con } \\
\text { la gestión responsable de sus grupos de interés. }\end{array}$ & 3,30 & 0,52 & 0,69 & 0,49 & \\
\hline $\begin{array}{l}\text { Desarrollo de mecanismos que aseguren la transparencia } \\
\text { de información y el respeto de los derechos de los } \\
\text { inversores mayoritarios y minoritarios. }\end{array}$ & 4,47 & 0,50 & 0,78 & 0,61 & \\
\hline
\end{tabular}


Un instrumento de medida para conocer las tendencias de los directivos en la priorización de las acciones de Responsabilidad Social Empresarial (RSE)

(Continuación)

\begin{tabular}{|c|c|c|c|c|c|}
\hline \multicolumn{6}{|c|}{ FACTOR 6: PRIORIDAD EN EL ÁMBITO DE LA OFERTA DE PRODUCTOS Y SERVICIOS AL MERCADO } \\
\hline Variable & $\begin{array}{l}\text { Puntuación } \\
\text { media }\end{array}$ & $\begin{array}{l}\text { Carga } \\
\text { factorial }\end{array}$ & $\begin{array}{c}\text { MSA } \\
\text { individual }\end{array}$ & $\begin{array}{l}\text { Correlac. } \\
\text { ítem-total }\end{array}$ & $\begin{array}{l}\text { Alpha de } \\
\text { Cronbach } \\
\text { por factor }\end{array}$ \\
\hline $\begin{array}{l}\text { Incorporación en la planificación estratégica de objeti- } \\
\text { vos vinculados con la mejora de productos y de la } \\
\text { atención y servicio al cliente. }\end{array}$ & 4,67 & 0,85 & 0,58 & 0,72 & 0,863 \\
\hline $\begin{array}{l}\text { Asignación de recursos financieros, tecnológicos, ma- } \\
\text { teriales y humanos y definición de instancias formales } \\
\text { responsables de la mejora de productos y de la aten- } \\
\text { ción y servicio al cliente. }\end{array}$ & 4,68 & 0,83 & 0,65 & 0,77 & \\
\hline $\begin{array}{l}\text { Desarrollo de políticas para asegurar la preservación de } \\
\text { la seguridad y privacidad del cliente. }\end{array}$ & 4,85 & 0,78 & 0,57 & 0,69 & \\
\hline $\begin{array}{l}\text { Desarrollo de un sistema de información al directorio } \\
\text { sobre efectos positivos y negativos de los productos y } \\
\text { servicios ofrecidos. }\end{array}$ & 4,65 & 0,72 & 0,72 & 0,72 & \\
\hline $\begin{array}{l}\text { Compromiso con las condiciones y garantías pactadas } \\
\text { con los clientes. }\end{array}$ & 4,83 & 0,63 & 0,66 & 0,65 & \\
\hline $\begin{array}{l}\text { Evaluación y reducción de posibles riesgos para el } \\
\text { éxito del negocio debido al tipo de operación que realiza } \\
0 \text { a sus sistemas internos de gestión. }\end{array}$ & 4,51 & 0,60 & 0,80 & 0,57 & \\
\hline $\begin{array}{l}\text { Desarrollo y promoción de políticas explícitas de publi- } \\
\text { cidad y promoción honesta. }\end{array}$ & 4,41 & 0,48 & 0,66 & 0,49 & \\
\hline $\begin{array}{l}\text { Capacitación de las diversas instancias de la empresa } \\
\text { (propietarios, directivos y trabajadores) en la mejora de } \\
\text { productos y de la atención y servicio al cliente. }\end{array}$ & 4,67 & 0,41 & 0,78 & 0,54 & \\
\hline
\end{tabular}


Un instrumento de medida para conocer las tendencias de los directivos en la priorización de las acciones de Responsabilidad Social Empresarial (RSE)

Anexo 6

Análisis de la validez divergente o discriminante

\begin{tabular}{|c|c|c|c|c|c|c|c|c|}
\hline \multicolumn{9}{|c|}{ Correlaciones } \\
\hline \multicolumn{2}{|l|}{ Tau_b de Kendall } & \multirow{2}{*}{$\begin{array}{c}\begin{array}{c}\text { ESCALA } \\
\text { MEDOAMBIENTAL }\end{array} \\
1\end{array}$} & \multirow{2}{*}{$\begin{array}{r}\text { ESCALA } \\
\text { LABORAL } \\
\mathbf{0 , 2 3 4} \\
\end{array}$} & \multirow{2}{*}{$\begin{array}{r}\begin{array}{r}\text { ESCALA } \\
\text { SOCIAL }\end{array} \\
0,523 \\
\end{array}$} & \multirow{2}{*}{$\begin{array}{c}\text { ESCALA } \\
\text { GESTÓNDELA } \\
\text { CADENADE } \\
\text { SUMNISTRO } \\
\mathbf{0 , 4 0 0} \\
\end{array}$} & \multirow{2}{*}{$\begin{array}{c}\text { ESCALA } \\
\text { TRANSPARENGIA, } \\
\text { VALORENY } \\
\text { GOBIERNO } \\
\text { CORPORATIVO } \\
\mathbf{0 , 3 2 3} \\
\end{array}$} & \multirow{2}{*}{$\begin{array}{c}\text { ESCALA } \\
\text { OFRTADE } \\
\text { PRODUCTOSY } \\
\text { SERMCOOS AL } \\
\text { MERCADO } \\
\mathbf{0 , 1 5 3} \\
\end{array}$} & \multirow{3}{*}{$\begin{array}{c}\text { Alpha de } \\
\text { Cronbach } \\
0,955\end{array}$} \\
\hline \multirow{3}{*}{$\begin{array}{c}\text { ESCALA } \\
\text { MEDIOAMBIENTAL }\end{array}$} & Correlation coeficient & & & & & & & \\
\hline & Sig. (2-tailed) & & $0,001^{\star \star}$ & $0,000^{\star *}$ & $0,000^{\text {t* }}$ & $0,000^{\text {t* }}$ & $0,039^{*}$ & \\
\hline & $\mathrm{N}$ & 100 & 100 & 100 & 100 & 100 & 100 & \\
\hline \multirow{3}{*}{ ESCALALABORAL } & Correlation coeficient & 0,234 & 1 & 0,388 & 0,298 & 0,390 & 0,402 & \multirow{3}{*}{0,917} \\
\hline & Sig. (2-tailed) & $0,001^{* *}$ & \multirow[b]{2}{*}{100} & $0,000^{\star *}$ & $0,000^{\star *}$ & $0,000^{\text {t* }}$ & $0,000^{\star *}$ & \\
\hline & $\mathrm{N}$ & 100 & & 100 & 100 & 100 & 100 & \\
\hline \multirow{3}{*}{ ESCALA SOCIAL } & Correlation coeficient & 0,523 & 0,388 & 1 & 0,353 & 0,354 & 0,191 & \multirow{3}{*}{0,939} \\
\hline & Sig. (2-tailed) & $0,000^{*+}$ & $0,000^{\star *}$ & \multirow[b]{2}{*}{100} & $0,000^{* *}$ & $0,000^{t *}$ & $0,010^{\star *}$ & \\
\hline & $\mathrm{N}$ & 100 & 100 & & 100 & 100 & 100 & \\
\hline \multirow{3}{*}{$\begin{array}{c}\text { ESCALAGESTIÓNDE } \\
\text { LACADENADE } \\
\text { SUMINISTRO } \\
\end{array}$} & Correlation coeficient & 0,400 & 0,298 & 0,353 & 1 & 0,284 & 0,351 & \multirow{3}{*}{0,922} \\
\hline & Sig. (2-tailed) & $0,000^{* *}$ & $0,000^{\star *}$ & $0,000^{\star *}$ & \multirow[b]{2}{*}{100} & $0,000^{\star *}$ & $0,000^{\star *}$ & \\
\hline & $\mathrm{N}$ & 100 & 100 & 100 & & 100 & 100 & \\
\hline \multirow{3}{*}{$\begin{array}{c}\text { ESCALA } \\
\text { TRANSPARENCIA, } \\
\text { VALORESY } \\
\text { GOBIERNO } \\
\text { CORPORATIVO } \\
\end{array}$} & Correlation coeficient & 0,323 & 0,390 & 0,354 & 0,284 & 1 & 0,449 & \multirow{3}{*}{0,913} \\
\hline & Sig. (2-tailed) & $0,000^{* *}$ & $0,000^{\star *}$ & $0,000^{\star *}$ & $0,000^{* *}$ & & $0,000^{\star *}$ & \\
\hline & N & 100 & 100 & 100 & 100 & 100 & 100 & \\
\hline \multirow{3}{*}{$\begin{array}{l}\text { ESCALAOFERTADE } \\
\text { PRODUCTOSY } \\
\text { SERVCIOSAL } \\
\text { MERCADO }\end{array}$} & Correlation coeficient & 0,153 & 0,402 & 0,191 & 0,351 & 0,449 & 1 & \multirow{3}{*}{0,863} \\
\hline & Sig. (2-tailed) & $0,039^{*}$ & $0,000^{\star *}$ & $0,010^{\star *}$ & $0,000^{* *}$ & $0,000^{\text {t* }}$ & & \\
\hline & $\mathrm{N}$ & 100 & 100 & 100 & 100 & 100 & 100 & \\
\hline
\end{tabular}

** La correlación es significativa al nivel 0,01 (2 colas).

* La correlación es significativa al nivel 0,05 (2 colas) 